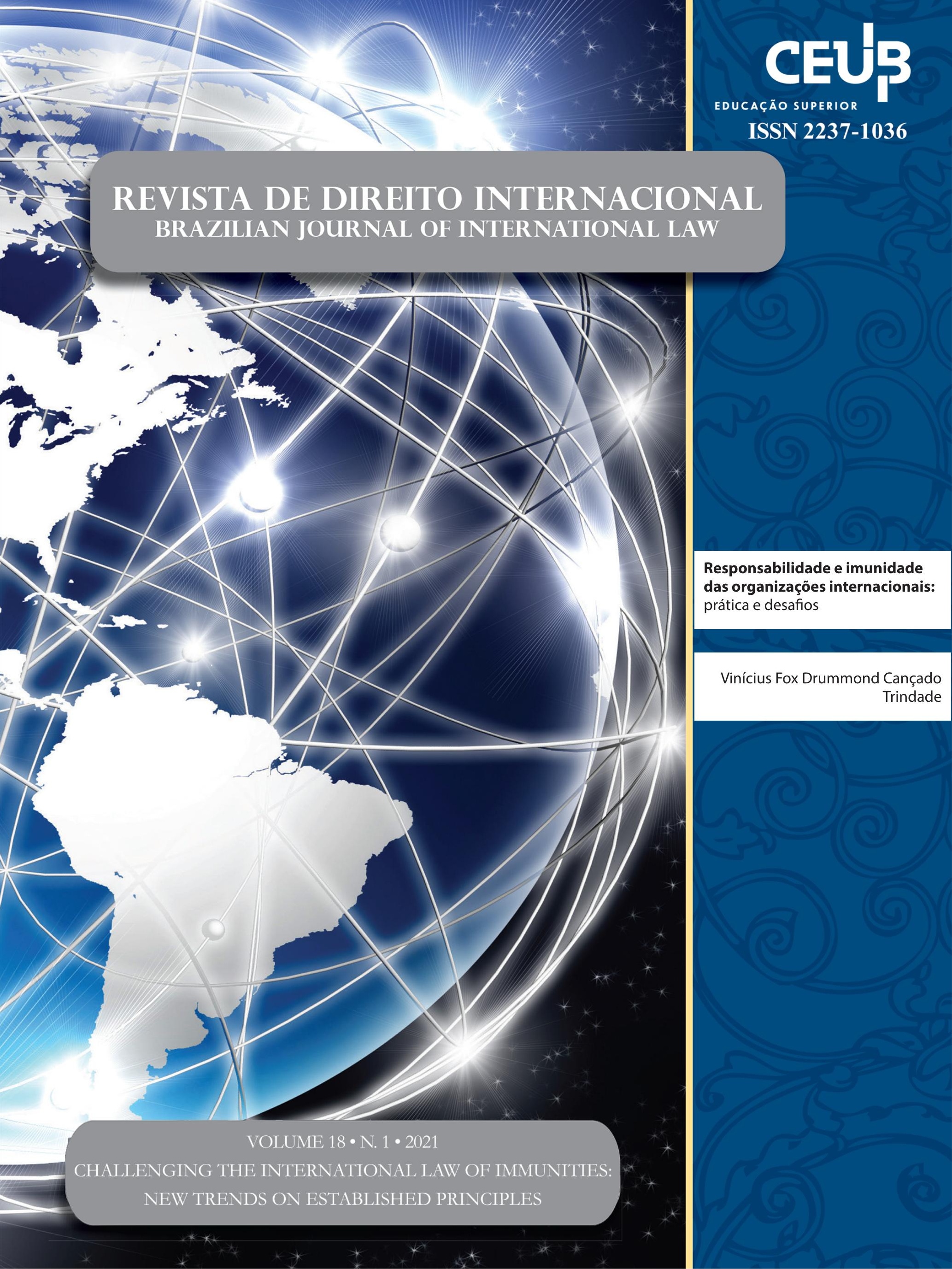


EDITORIAL

Challenging the International Law of Immunities: New Trends on Established Principles? An introduction to the special issue ............................................ 14

Lucas Carlos Lima, Loris Marotti e Paolo Palchetti

CrôniCAS........................................................................................ 17

RESPONSABILIDADE E IMUNIDADE DAS ORgANIZAÇÕES INTERNACIONAIS: PRÁTICA E DESAFIOS ...19 Vinícius Fox Drummond Cançado Trindade

The JURISDiCTIONAL IMMUNITY OF INTERNATIONAL ORgaNiZATIONS BEFORE THE BRAZILIAN SuPREMe Federal Court.

Bárbara Tuyama Sollero

The Law of State Immunity before the Brazilian Supreme Court: what is at stake WITH THE "ChANGRI-LA" CASE?

Aziz Tuffi Saliba e Lucas Carlos Lima

\section{Dossiê: Challenging the International Law of Immunities: New Trends} on Established Principles?

State Immunity and the Rights of Employees: Lights and Shadows of the Strasbourg COURT's JURISPRUdENCE .61

Pierfrancesco Rossi

A human Rights-BASEd CHALlENGE: THE KEY TO UNLOCK THE UN'S IMMUNiTY PROBLEM?...79 Héloïse Guichardaz

IMMUNITIES OF STATE OFFICIALS AND THE "FUNDAMENTALLY DIFFERENT NATURE" OF INTERNATIONAL COURTS: THE APPEALS CHAMBER DECISION IN THE JORDAN REFERRAL RE AL BASHIR ...97 Rita Guerreiro Teixeira e Hannes Verheyden 
IMUNIDADE DE JURISDIÇÃo dOS EsTADOS: O CAMINHO PARA A RELATIVIZAÇÃo

Vinícius Assis da Silveira, Luiz Felipe Costa Santana e Valesca Raizer Borges Moschen

The IMmUNity OF INTERNATIONAL ORganizations IN LABOUR DispUTES. DeVElopments BEFORE INTERNATIONAL TRIBUNALS, NATIONAL COURTS AND THE COLOMBIAN JURISDICTION ..... 137 Walter Arévalo-Ramirez e Ricardo Abello-Galvis

Imunidade de Jurisdição dos Estados E Poder Executivo brasileiro: os Pareceres dos CONSULTORES JURÍDICOS DO ITAMARATY

George Rodrigo Bandeira Galindo

Artigos SOBRe outros temas

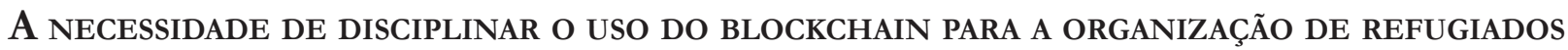
PELO DIREITO INTERNACIONAL. 195

Agatha Gonçalves Santana, Carla Noura Teixeira e Otavio Noura Teixeira

O TRABALHO INFANTIL DE MIGRANTES E REFUgIADOS VENEZUELANOS NO BRASIL

André Viana Custódio e ohana Cabral

THE NEW BRAZILIAN ANTI-TRAFFICKING LAW: CHALLENGES AND OPPORTUNITIES TO COVER THE NORMATIVE LACK . 243 Waldimeiry Correa da Silva

¿SON PARTE DEL BLOQUE DE CONSTITUCIONALIDAD LOS TRATADOS INTERNACIONALES DE DERECHOS HuMANOS DE LA OEA EN CHILE?: AVANCES EN BASE A LA DOCTRINA, NORMATIVA Y JURISPRUDÊNCIA. 270

Juan Pablo Díaz Fuenzalida

O Tratado de Saint-Germain-En-Laye e os Efeitos do instituto da “opÇão” Sobre a CONDIÇÃO JURÍDICA DOS DESCENDENTES DE CIDADÃOS AUSTRÍACOS TRENTINO-TIROLÊSES ......290 Arno Dal Ri Jr. e Andrey José Taffner Fraga

Control Judicial de la Corte Interamericana de Derechos Humanos y Programas Masivos de Reparaciones: Hacia un Enfoque más Matizado .309 Juan Carlos Ochoa-Sánchez 
JuSTICIABILIDADE DIRETA DOS DIREITOS ECONÔMICOS, SOCIAIS, CULTURAIS E AMBIENTAIS NA

Corte Interamericana DE Direitos Humanos..........................................................334

Augusto Antônio Fontanive Leal e Guilherme Massaú

How the indigenous case of Xukuru before the Inter-American Court of Human RiGHTS CAN INSPIRE DECOLONIAL COMPARATIVE STUDIES ON PROPERTY RIGHTS..........................353

Flavianne Fernanda Bitencourt Nóbrega e Camilla Montanha 


\title{
Responsabilidade e imunidade das organizações internacionais: prática e desafios*
}

\author{
Vinícius Fox Drummond Cançado Trindade**
}

\section{Introdução}

O século XX foi cenário de importante desenvolvimento na estrutura da comunidade internacional: a criação, a multiplicação e a especialização das organizações internacionais. As relações jurídicas no interior dessa comunidade, anteriormente monopolizadas pela atuação dos Estados, passaram a envolver ampla gama de sujeitos de direito, o que tem demandado a codificação e o desenvolvimento progressivo do Direito Internacional Público.

As organizações internacionais têm chamado, frequentemente, seus Estados Membros a respeitarem os direitos humanos, os princípios de boa governança e as normas internacionais. Uma tendência recente, no entanto, tem sido a de questionar se as próprias organizações internacionais têm respeitado essas normas. Episódios recentes, como os crimes cometidos em Ruanda e na ex-Iugoslávia, nos anos 1990, as sanções dirigidas (targeted sanctions) adotadas pelo Conselho de Segurança das Nações Unidas, nos anos 2000, e episódios de negligência em missões de paz, nos anos 2010, levam a crer que essas organizações podem, igualmente, cometer atos internacionalmente ilícitos.

A prática e jurisprudência internacionais demonstram que, assim como os Estados, as organizações internacionais estão aptas a exercer direitos e a contrair obrigações internacionais. Tornar as organizações internacionais mais responsáveis, sujeitas a sanções sempre que cometerem atos internacionalmente ilícitos, é desdobramento necessário do desenvolvimento do primado do direito (rule of law) no sistema internacional. É nesse contexto que se inserem os Artigos sobre Responsabilidade das Organizações Internacionais, elaborados pela Comissão de Direito Internacional das Nações Unidas (CDI).

A seção inicial deste artigo tem o propósito de demonstrar que não há substantiva lacuna normativa sobre o tema, mas sim ausência de prática e de aplicação das regras adotadas pela Comissão de Direito Internacional. A seção seguinte tem como principal objetivo analisar o déficit institucional, interna e externamente, para avaliação da licitude de atos cometidos por organizações internacionais e determinação de sua eventual responsabilidade. As seções finais têm o propósito de avaliar os desafios suscitados pela aplicação da imunidade jurisdicional das organizações internacionais. São tratados o fundamento, as fontes e o desenvolvimento histórico das imunidades jurisdicionais das organizações internacionais. Examinam-se, igualmente, os limites dessas imunidades e a falta de consistência nas jurisprudências de tribunais regionais e domésticos.

O artigo apontará que, do ponto de vista normativo, o Direito Internacional Público oferece alternativas normativas para que as organizações

** Mestre em Direito pela UnB. Diplomata de carreira.

E-mail: foxtrindade@gmail.com
* Recebido em 30/09/2020 Aprovado em 21/07/2021 
internacionais sejam responsabilizadas nos planos internacional e doméstico. Os Artigos sobre Responsabilidade das Organizações Internacionais, preparados pela CDI, ocupam papel central nesse arcabouço normativo, embora sejam muito mais um reflexo do desenvolvimento progressivo do Direito Internacional do que sua codificação. Os principais desafios para o desenvolvimento consistente da prática internacional da responsabilização das organizações internacionais residem, na verdade, na ausência de mecanismos de controle de legalidade — internos e externos — e na aplicação absoluta da imunidade jurisdicional.

\section{Os artigos sobre responsabilidade das organizações internacionais}

Na prática internacional, a personalidade jurídica das organizações deixou de ser contestada desde 1949, com a paradigmática Opinião Consultiva da CIJ em Reparations for Injuries. ${ }^{1}$ Como sujeitos de direito, essas organizações estão obrigadas a observar o direito internacional geral, seus instrumentos constitutivos e tratados de que sejam Partes. ${ }^{2}$ Assim como os Estados, devem responder quando falham em observar obrigações oriundas dessas fontes. Contudo, diferentemente dos Estados, a prática internacional na área da responsabilidade internacional é significativamente mais restrita.

O direito da responsabilidade constitui verdadeiro epicentro de um sistema jurídico, porquanto fornece as conexões lógicas de interdependência entre a natureza dos direitos, a estrutura das obrigações e a definição das sanções. ${ }^{3}$ A negação desse instituto jurídico implicaria ineficácia do direito internacional, uma vez que a inexistência de regras acerca da atribuição de responsabilidades suprimiria o dever dos Estados e das organizações internacionais de se comportarem de acordo com as obrigações por eles assumidas. ${ }^{4}$ Com o intui-

\footnotetext{
${ }^{1}$ CORTE INTERNACIONAL DE JUSTIÇA. Reparations for injuries suffered in the service of the United Nations, Advisory Opinion. I.C.J. Reports, 1949.

2 CORTE INTERNACIONAL DE JUSTIÇA. Interpretation of the Agreement of 25 March 1951 between the WHO and Egypt, Advisory Opinion. I.C.J. Reports, 1980. p. 73.

3 DUPUY, Pierre-Marie. Le fait générateur de la responsabilité internationale des États. Recueil des Cours de l'Académie de Droit International, v. 188, n. 5, 1984. p. 21.

4 VERDROSS, Alfred. Derecho internacional publico. Madrid: Aguilar, 1976. p. 353
}

to de preencher lacunas na regulamentação do direito internacional, a CDI apresentou o Projeto de Artigos sobre Responsabilidade das Organizações Internacionais (2011), em seguimento ao Projeto de Artigos sobre Responsabilidade dos Estados (2001). Em que pese a importância desse tema para o direito internacional, ambos os documentos desenvolvidos pela CDI permanecem na forma de projeto de artigos, sem que tenham sido adotados pelos Estados como tratados.

A responsabilidade das organizações internacionais já havia sido identificada pela CDI como questão que merecia especial atenção desde 1963 , no primeiro relatório sobre relações entre Estados e organizações intergovernamentais. ${ }^{5} \mathrm{O}$ tema foi suscitado em diversas ocasiões nos debates do Sub-Comitê sobre Responsabilidade dos Estados, quando se discutiam o escopo e a delimitação do futuro Projeto de Artigos sobre Responsabilidade dos Estados. Em 1969, a CDI tomou a decisão de que "[...] o estudo da responsabilidade de outros sujeitos de Direito Internacional, tais como organizações internacionais, deveria ser deixado de lado". ${ }^{6}$

Não obstante esse antecedente, apenas em 2000, a CDI concluiu que a responsabilidade de organizações internacionais constituía tema para seu programa de trabalho de longo-prazo. Ao tomar ciência disso, a Assembleia Geral das Nações Unidas (AGNU) adotou a resolução 56/82, de 12 de dezembro de 2001, solicitando à CDI que começasse o trabalho sobre esse tema. No ano seguinte, o Professor Giorgio Gaja foi indicado pela CDI para se tornar o Relator do Grupo de Trabalho que seria criado para tratar do tema.

De 2003 a 2011, a CDI recebeu oito relatórios de Giorgio Gaja, bem como comentários de governos e de organizações internacionais. Em 2011, a CDI adotou, definitivamente, os Artigos sobre Responsabilidade das Organizações Internacionais, divididos em seis partes: (i) introdução, com os artigos 1 a 2; (ii) ato internacionalmente ilícito de uma organização internacional, dos artigos 3 a 27; (iii) conteúdo da responsabilidade internacional de uma organização internacional, referente aos artigos 28 a 42; (iv) implementação da responsabili-

\footnotetext{
5 UN Doc. A/CN.4/161 e Add. 1, "First report on relations between States and inter-governmental organizations", 1963, p. 184: "O contínuo aumento do escopo de atividades de organizações internacionais provavelmente dará novas dimensões ao problema da responsabilidade das organizações internacionais", tradução nossa. 6 UN. Doc A/CN.4/217 e Add.1, "First report on State responsibility”, 1969, p. 140, tradução nossa.
} 
dade internacional de organizações internacionais, com os artigos 43 a 57; (v) responsabilidade do Estado em conexão com a conduta de uma organização internacional, referente aos artigos 58 a 63; e (vi) provisões gerais, dos artigos 64 a 67.

A CDI recomendou à AGNU que se tomasse nota dos Artigos sobre Responsabilidade das Organizações Internacionais e que se considerasse, eventualmente, a elaboração de tratado sobre o tema. ${ }^{7}$. Seguindo essa orientação, a AGNU anexou os artigos à resolução 66/100 e decidiu retomar a questão em sua $69^{\mathrm{a}}$ sessão, em 2014, para eventual decisão sobre a forma final que deveria ser conferida aos artigos. ${ }^{8}$ Desde então, o tema tem sido debatido entre Estados Membros na Sexta Comissão da AGNU, sem muito progresso. A maioria dos países preferiu não tomar medidas adicionais, com base em dois argumentos principais: (i) os artigos refletiram o desenvolvimento progressivo do direito internacional, e não a codificação de costume internacional; e (ii) teria havido pouca oportunidade para a aplicação dos artigos e surgimento de prática internacional sobre a matéria. ${ }^{9}$ Nesse contexto, acordou-se postergar novamente a decisão sobre o formato dos artigos para a $72^{\mathrm{a}}$ sessão da AGNU, em 2017, bem como solicitar nova rodada de comentários de governos e de organizações internacionais e estudo do Secretariado sobre a aplicação dos artigos por órgãos internacionais de solução de controvérsias. ${ }^{10}$

Os novos comentários recebidos em 2017 revelaram que houve pouco progresso no tema. No período de 2004 a 2016, o Secretariado identificou apenas nove casos na jurisprudência internacional com referências aos Artigos. Na nova rodada de comentários, questionou-se, novamente, a escassez de prática internacional sobre o tema, em comparação aos Artigos sobre Responsabilidade dos Estados. Interessante notar que 24 organizações internacionais submeteram comentários conjuntos que destacam o caráter não consensual de

7 UN Doc. A/66/10, "Official Records of the General Assembly, Sixty-sixth Session, Supplement No. 10”, para. 85.

8 UN Doc. A/Res/66/100, "Responsibility of international organizations", para. 4.

9 UN Doc. A/C.6/69/SR.18, "Summary record of the 18th meeting of the Sixth Committee". Cf. nesse sentido o pronunciamento das delegações da Dinamarca, em nome dos países nórdicos, Reino Unido, Portugal, Grécia e Estados Unidos. Pronunciaram-se a favor de realização de conferência internacional para sua adoção em formato de convenção as delegações de Cuba , Rússia e Micronésia.

${ }^{10}$ UN Doc. A/RES/69/126, "Responsibility of international organizations". certos artigos. Consideraram que, como exercício de desenvolvimento progressivo do direito internacional, e não de codificação, seria essencial atingir maior nível de consenso no tema. Por fim, alertaram duramente: "porque muitos dos artigos permanecem controversos e em grande medida não apoiados pela prática, instamos que tomem significativa cautela ao se apoiarem nos artigos como uma declaração oficial do direito positivo". ${ }^{11}$ Em vista da ausência de consenso, a decisão procedimental adotada foi de solicitar nova rodada de comentários, atualização do estudo do Secretariado sobre a prática internacional e postergar a decisão sobre o formato dos artigos para a $75^{a}$ sessão da AGNU, em 2020. ${ }^{12}$

Em busca de uma resposta final às reiteradas críticas aos Artigos, Giorgio Gaja foi enfático ao listar três pontos que teriam dificultado os trabalhos da CDI: (i) a pouca informação submetida por Estados e organizações internacionais; (ii) o material pouco esclarecedor produzido pela doutrina nessa área; e (iii) a expressiva relutância da maioria das organizações em submeter controvérsias com Estados ou com outras organizações à solução por terceiros. ${ }^{13}$ Considera-se, neste artigo, que esse último ponto é o principal óbice ao desenvolvimento de prática internacional, podendo ser explicado por distintos fatores, como a falta de locus standi de organizações internacionais perante tribunais internacionais; a ausência de mecanismos de controle de legalidade de seus atos internos; e, no âmbito doméstico, a aplicação da imunidade absoluta de jurisdição.

\section{Mecanismos de controle de legalidade}

Nos últimos anos, observou-se expressivo número de trabalhos acadêmicos que conferem ênfase à responsabilidade dos Estados Membros de organizações internacionais pelo cometimento de atos internacionalmente ilícitos. ${ }^{14}$ Estudos nesse sentido utilizam-se de conceitos

11 UN Doc. A/72/80, "Responsibility of international organizations. Comments and informations received from Governments and international organizations", p. 7, tradução nossa.

12 UN Doc. A/RES/72/122, "Responsibility of international organizations".

${ }^{13}$ UN Doc. A/CN.4/640, "Eighth report on responsibility of international organizations", de 14 de março de 2011, pp. 5-6.

${ }^{14}$ BARROS, Ana Sofia; RYNGAERT, Cedric; WOUTERS, Jan (eds.) International organizations and member state responsibility: critical perspectives. Leiden: Brill Nijhoff, 2017; NOLLKAEMPER, André; 
como responsabilidade compartilhada, abuso da personalidade jurídica e uso do véu institucional, para defender a responsabilização dos Estados Membros. Alguns desses estudos diagnosticam o problema como sendo essencialmente de lacuna normativa. ${ }^{15}$ Não se pretende, neste artigo, rejeitar essas avaliações, mas sim explorar outro aspecto do problema: o déficit de mecanismos para a responsabilização de organizações internacionais.

Esse déficit institucional pode apresentar-se tanto na dimensão interna da organização quanto na dimensão externa. $\mathrm{Na}$ dimensão interna, diz respeito à ausência de mecanismos de controle de legalidade de seus atos: com raras exceções, faltam às organizações internacionais instâncias internas de controle de legalidade. Já a dimensão externa diz respeito à falta de locus standi por parte das organizações internacionais perante tribunais internacionais.

As organizações internacionais, como sujeitos de direito internacional público, estão vinculadas (i) a seus instrumentos constitutivos; (ii) a tratados de que sejam partes; e (iii) a obrigações previstas pelo direito internacional geral. Com base nessa premissa, é possível identificar três critérios para a realização do controle de legalidade sobre atos das organizações internacionais, a saber: (i) critérios quanto à competência, extraídos geralmente de tratados constitutivos; (ii) critérios formais de direito processual, consubstanciados em regras de procedimento internas; e (iii) critérios de direito material.

PLAKOKEFALOS, Ilias. Principles of shared responsibility in international law: an appraisal of the state of the art. Cambridge: Cambridge University Press, 2014. p. 16; BLOKKER, N. Abuse of the Member: questions concerning Draft Article 16 of the Draft Articles on Responsibility of International Organizations. In: International Organizations Law Review, n. 35, v. 7, pp. 35-48; KLEIN, P. The attribution of acts to international organizations. In: CRAWFORD, J; PELLET, A.; OLLESON, S. (eds.). The law of international responsibility. Oxford: Oxford University Press, 2010; KUIJPER, P. J.; PAASIVIRTA, E. EU international responsibility and its attribution: from the inside looking out. In: EVANS, M.; KOUTRAKOS, P. (eds.). The international responsibility of the European Union. Oxford: Hart Publishing, 2013; PAASIVIRTA, E. Responsibility of a member state of an international organization: where will it end? comments on Article 60 of the ILC Draft on the Responsibility of International Organizations. International Organizations Law Review, v. 7, n. 49, p. 49-61, 2010; REINISCH, A. Aid or assistance and direction and control between state and international organizations in the commission of internationally wrongful acts. International Organizations Law Review, v. 7, n. 63, p. 63-77, 2010.

15 CRAWFORD, James. The ILC's articles on responsibility of states for internationally wrongful acts: a retrospect. The American Journal of International Law, v. 96, n. 4, p. 874-890, out. 2002. p. 879.
Apesar dessas limitações e dos critérios possíveis para realização do controle de legalidade, são poucas as instâncias internas a que se possa recorrer para contestar atos de organizações internacionais. Alguns exemplos são os tribunais administrativos para questões trabalhistas; ${ }^{16}$ os mecanismos de Ombudsperson nas $\mathrm{Na}$ ções Unidas, para recebimento de denúncias; ${ }^{17}$ o Painel Consultivo de Direitos Humanos, criado no âmbito da UNMIK - embora não tenha logrado êxitos significativos, segundo sua própria avaliação — ${ }^{18}$ e o Painel de Inspeção do Banco Mundial — um mecanismo independente de reclamações para indivíduos e grupos adversamente afetados por projetos dessa instituição.

As opções de recurso a instâncias externas também são limitadas, uma vez que organizações internacionais não contam com locus standi in judicio perante jurisdições gerais — como a Corte Internacional de Justiça ("CIJ") — e, com raras exceções (União Europeia), são Parte de tratados que preveem mecanismos de solução de controvérsias. ${ }^{19}$ Cabe reconhecer que o Tribunal de Justiça

16 Um dos mais antigos exemplos de mecanismo de adjudicação interna em organizações internacionais é o Tribunal Administrativo da Liga das Nações, criado em 1927, para dirimir questões trabalhistas de funcionários do Secretariado. Com o fim da Liga das Nações, o Tribunal foi transferido para a estrutura institucional da Organização Internacional do Trabalho ("OIT") e, desde 1949, tem jurisdição também sobre outras organizações internacionais que tenham reconhecido sua competência, como a Organização Mundial da Saúde ("OMS”) e outras agências especializadas. O Tribunal recebe petições contra decisões tomadas previamente pela organização em questão, desde que se tenham esgotado os recursos administrativos internos existentes. Outra possibilidade de recurso para funcionários das Nações Unidas — que na maioria dos casos não podem recorrer às jurisdições trabalhistas nacionais por conta dos privilégios e imunidades — é o Tribunal de Controvérsias da ONU (UN Dispute Tribunal), de primeira instância; e o Tribunal de Apelações da ONU (UN Appeals Tribunal), de segunda instância. Esses dois órgãos substituíram, em 2009, o então Tribunal Administrativo das Nações Unidas ("UNAT”), que havia sido estabelecido em 1949 pela AGNU. Outras organizações internacionais também contam com tribunais administrativos internos para questões trabalhistas, como o Conselho da Europa, a União Europeia, a Organização dos Estados Americanos ("OEA"), o Banco Mundial, o Banco de Desenvolvimento Asiático e o Banco de Desenvolvimento da África.

17 Cf., por exemplo, Escritório do Ombudsperson da Administração Transitório do Timor Leste; e Ombudsperson para o Comitê de Sanções do ISIS (Da'esh) e Al-Qaeda.

18 UNMIK. Final Report of the Human Rights Advisory Panel, de 30 de junho de 2016. 2016. p. 86. Dsponível em: http://www.unmikonline. org/hrap/Eng/Pages/Annual-Report. aspx Acesso em: 2 dez. 2018. 19 BLOKKER, Niels. Member state responsibility for wrongdoings of international organizations. In: BARROS, Ana Sofia; RYNGAERT, Cedric; WOUTERS, Jan (eds.) International organizations and member state responsibility: critical perspectives. Leiden: Brill Nijhoff, 2017. p. 45. 
da União Europeia (“TJUE") e a Corte Europeia de Direitos Humanos ("CEDH") foram chamados a realizar o controle de atos do CSNU e deram importante contribuição jurisprudencial. ${ }^{20}$ Todavia, alguns críticos do controle de legalidade realizado por tribunais internos e regionais têm sustentado que, se realmente alguma Corte deveria exercer papel nessa seara, esta seria a CIJ.

Não há dúvida de que a CIJ, como principal órgão judiciário das Nações Unidas, detém plena legitimidade para realizar o controle de legalidade sobre os atos do CSNU. No entanto, em distintas ocasiões a CIJ absteve-se de realizar controle sobre a legalidade de resoluções do CSNU. Esse problema tem surgido sempre como questão incidental, tanto em casos contenciosos (e.g. Lockerbie, de 1992 $)^{21}$ quanto em opiniões consultivas (e.g. Namíbia, de 1971). ${ }^{22}$ Até o presente momento, a CIJ tem tomado posições ambíguas e evasivas sobre a sua competência para realizar o controle. Essa posição extremamente reticente do principal órgão judiciário das Nações Unidas não foi seguida nem pelos tribunais internacionais penais ad hoc, ${ }^{23}$ nem pelos órgãos de

${ }^{20}$ CORTE EUROPEIA DE DIREITOS HUMANOS. Bebrami and Bebrami v. France and Saramati v. France, Germany and Norway. Decisão de 2 de maio de 2007; CORTE EUROPEIA DE DIREITOS HUMANOS. Case of Bosphorus Hava Yollari Turizm Vê Ticaret Anonim Sirketi v. Ireland. In Reports of Judgments and Decisions 2005, VI. Julgamento de 30 de junho de 2005. p. 155-156; CORTE EUROPEIA DE DIREITOS HUMANOS. Case of Beric and others v. Bosnia and Herzegovina, application Nos. 36357/04, 36360/04, 38346/04, 41705/04, 45190/04, 45578/04, 45579/04, 45580/04, 91/05, $97 / 05,100 / 05,101 / 05,1121 / 05,1123 / 05,1125 / 05,1129 / 05$, $1132 / 05,1169 / 05,1172 / 05,1175 / 05,1177 / 05,1180 / 05,1185 / 05$, 20793,05 e 25496/05, decision (admissibility), 16 October 2007, p 8; CORTE EUROPEIA DE DIREITOS HUMANOS (Grand Chamber). Al-Jedda v. United Kingdom, application No. 27021/08, judgment, 7 de julho de 2011. p. 84-86; UNIÃO EUROPEIA. Tribunal de Justiça. Acórdão de 3 de setembro de 2008. Caso Yassin Abdullah Kadi, Al Barakkat International Foundation $v$. Conselho da União Européia \& Comissão das Comunidades Europeias, Reino Unido da GrãBretanha e da Irlanda do Norte. C 285/2, 8 de novembro de 2008.

${ }^{21}$ CORTE INTERNACIONAL DE JUSTIÇA. Questions of interpretation and application of the 1971 Montreal Convention arising from the Aerial Incident at Lockerbie (Libyan Arab Jamahiriya v. United Kingdom). I.C.J. Reports, 1992.

${ }^{22}$ CORTE INTERNACIONAL DE JUSTIÇA. Legal consequences for States of the continued presence of South Africa in Namibia (South West Africa) notwithstanding Security Council Resolution 276 (1970). I.C.J. Reports, 1971.

${ }^{23}$ No caso Tadic, o Tribunal Penal Internacional para a ex-Iugoslávia examinou a legalidade de seu próprio instrumento constitutivo, a resolução 827 de 1993 . O recorrente alegava que a criação do Tribunal pelo CSNU havia extrapolado os limites do capítulo VII da Carta. Defrontado com a questão do excesso de poder do CSNU, o Tribunal declarou que a adoção da resolução 827 ocorreu em conformidade com o artigo $41 \mathrm{da}$ Carta, como uma das medidas monitoramento dos Pactos Internacionais de 1966. ${ }^{24}$ Enquanto a CIJ não realizar o controle externo, é bem provável - e até mesmo salutar - que outras jurisdições o exerçam, a fim de preencher o vácuo jurídico-institucional que existe a esse respeito.

Tribunais regionais e mesmo internos têm examinado a legalidade de atos de organizações internacionais - ainda que indiretamente -, e alguns não hesitaram em declarar sua ilegalidade, tornando-os ineficazes no ordenamento jurídico nacional ou regional. Poucos, no entanto, têm fundamentado sua ratio decidendi em normas de direito internacional; de fato, a maioria tem baseado o controle de legalidade em garantias constitucionais ou em tratados regionais. É importante perceber que juízes internos e regionais têm ocupado um espaço negligenciado seja pela CIJ seja pelas próprias organizações internacionais. ${ }^{25}$

\section{Imunidade das organizações internacionais: origem, fundamento e evolução}

Diferentemente dos Estados, as organizações internacionais não possuem território próprio, razão pela qual dependem do acolhimento daquele sujeito para que possam realizar suas funções. Mais do que mero acolhimento, as organizações internacionais devem dis-

autorizadas pelo capítulo VII (TPII, 1995, p. 13). Asseverou, no entanto, que os poderes do CSNU não são ilimitados, por se tratar de um órgão de uma organização internacional inserida no quadro constitucional da Carta. O Tribunal concluiu que os poderes do Conselho de Segurança não podem ir além dos limites da jurisdição da organização nem entrar em conflito com o texto e espírito da Carta. ${ }^{24} \mathrm{O}$ impacto desproporcional das sanções econômicas sobre países como o Haiti e Iraque causaram danos tão graves sobre a população civil quanto as situações configuradas como ameaças à paz internacional que levaram à sua adoção. Não foi por coincidência que, em 1997, o Comitê dos Direitos Econômicos Sociais e Culturais das Nações Unidas publicou seu Comentário Geral n. 8 (E/C.12/1997/8), ressaltando que os direitos sociais, econômicos e culturais servem como limitações a regimes jurídicos estabelecidos por resoluções do CSNU, ainda que adotadas sob o capítulo VII da Carta. Já o Comitê de Direitos Humanos, no caso Sayadi v. Bélgica (petição n. 1472/2006 — U.N. Doc. CCPR/C/94/D/1472/2006, 29 de dezembro de 2008), concluiu que o que o Estado demandado tinha o dever de tomar todas as medidas necessárias para cessar a violação do direito em questão, o que significava a não observância de uma resolução do CSNU.

25 TRINDADE, Vinícius Fox Drummond Cançado. Controle de legalidade dos atos do Conselho de Segurança das Nações Unidas. Revista da Faculdade de Direito da UFMG, n. 62, 2013. 
por de garantias de que seu Estado de sede não buscará ações de ingerência em seu funcionamento, segundo o paradigma funcionalista do Direito das Organizações Internacionais. ${ }^{26}$ É nesse contexto que se afirmaram na comunidade internacional privilégios e imunidades às organizações internacionais e a seus funcionários, com o propósito de assegurar sua autonomia e livre funcionamento no território dos Estados em que se situam. ${ }^{27}$

Entre os privilégios e imunidades existentes, a imunidade jurisdicional tem sido, em particular, elemento central dos debates acadêmicos e da jurisprudência a respeito. A imunidade jurisdicional afasta a jurisdição do Estado local, podendo ocorrer tanto no processo de conhecimento quanto no de execução. Outros privilégios e imunidades, extensíveis a seus funcionários, incluem, inter alia, isenções tributárias, bem como inviolabilidade pessoal, de bens, de residência e de local de trabalho.

Importante classificar as imunidades jurisdicionais em dois grupos que contam com beneficiários distintos. O primeiro grupo de imunidades compreende os serviços diplomáticos e consulares, o regime de navios de guerra estrangeiros em águas nacionais e territoriais e o estatuto das tropas estrangeiras ocupantes. O segundo diz respeito ao Estado em face da jurisdição estatal estrangeira; por aplicação do Princípio Par in Parem non Habet Indicium, entende-se que, entre iguais, uma jurisdição não pode prevalecer sobre a outra. ${ }^{28}$ Embora os beneficiários desses dois grupos sejam distintos, cabe ressaltar que, em ambos os casos, a prerrogativa de imunidade cabe ao Estado - e apenas este pode renunciá-

\footnotetext{
26 A teoria predominante no Direito das Organizações Internacionais, o funcionalismo, tem-se mostrado presente em grande parte dos estudos acadêmicos e de decisões de tribunais internacionais desde a primeira metade do século XX. Como definição, o funcionalismo determina que as organizações internacionais foram criadas por seus Estados Membros para cumprir funções específicas e por eles determinadas. Uma das grandes narrativas que inspira o funcionalismo é a noção de progresso na comunidade internacional, a qual se desenvolveria, se organizaria e se integraria cada vez mais a partir da cooperação. O funcionalismo, aplicado ao Direito das Organizações Internacionais, esclarece o que essas instituições podem ou devem fazer, mas não oferece espaço suficiente para analisar como de fato estão se comportando, e como regras jurídicas poderiam ser desenvolvidas para suprir eventuais lacunas normativas.

${ }^{27}$ MOLL, Leandro de Oliveira. Imunidades internacionais: tribunais nacionais ante a realidade das organizações internacionais. Brasília: FUNAG, 2010. p. 19-20.

${ }^{28}$ MOLL, Leandro de Oliveira. Imunidades internacionais: tribunais nacionais ante a realidade das organizações internacionais. Brasília: FUNAG, 2010. p. 24-25. Há também a imunidade conferida a Chefes de Estado, que se encontra no meio-termo entre as duas categorias de beneficiários.
}

-la. É possível classificar as imunidades das organizações internacionais e de seus funcionários no primeiro grupo. No entanto, esse exercício de analogia deve ser empreendido com cautela, uma vez que as fontes das imunidades no Direito Internacional Público diferem sobremaneira.

A presente seção terá como objeto as imunidades jurisdicionais das organizações internacionais e seu lugar na busca de responsabilização desses sujeitos por atos internacionalmente ilícitos. Em primeiro lugar, será realizada breve análise sobre as origens da imunidade conferida às organizações internacionais. Em segundo, serão tratadas as atuais tendências no Direito das Organizações Internacionais em relação à imunidade jurisdicional desses sujeitos, com foco na possibilidade de relativização em casos de denegação do direito de acesso à justiça. O tratamento dessas imunidades em jurisdições regionais e nacionais será examinado, incluindo no sistema jurídico brasileiro, com vistas a examinar a atual prática internacional. Por fim, será considerada a possibilidade de relativização da imunidade jurisdicional das organizações internacionais diante da inexistência de mecanismos de controle interno, como forma de superar lacunas institucionais e com vistas a promover o primado do direito (rule of law) na comunidade internacional.

As imunidades têm como um de seus fundamentos a garantia do livre desempenho das atividades de agentes estatais estrangeiros em território de outro Estado, assegurando-lhes a inviolabilidade dos bens e a independência nas atividades oficiais que precisam ser exercidas. A Convenção de Viena sobre Relações Diplomáticas de 1961 reconhece, em seu preâmbulo, que "a finalidade de tais privilégios e imunidades não é beneficiar indivíduos, mas, sim, a de garantir o eficaz desempenho das funções das Missões diplomáticas, em seu caráter de representantes dos Estados". ${ }^{29}$

Princípio semelhante foi aplicado às organizações internacionais, para que estas e seus funcionários possam exercer suas funções com independência e autonomia, sobretudo em relação ao Estado-sede. O reconhecimento de um conjunto mínimo de privilégios e imunidades às organizações internacionais decorre do paradigma funcionalista, na medida em que visam ga-

\footnotetext{
${ }^{29}$ Cf. Convenção de Viena sobre Relações Diplomáticas de 1961, parágrafo preambular N. ${ }^{\circ} 4$.
} 
rantir que esses sujeitos de direito exerçam as funções que lhes foram atribuídas pelos Estados Membros.

Diferentemente dos Estados, cujas imunidades têm origem costumeira, as organizações internacionais gozam de imunidades decorrentes de tratados. Em geral, essas imunidades e privilégios têm como fonte (i) tratados constitutivos - a exemplo do artigo 105 da Carta das Nações Unidas e do artigo 133 da Carta da OEA -; (ii) acordos bilaterais de sede - como o Acordo de Sede entre o Governo da República Federativa do Brasil e a Organização do Tratado de Cooperação Amazônica (OTCA) —; e (iii) tratados multilaterais, sendo os casos mais significativos a Convenção sobre Privilégios e Imunidades das Nações Unidas de 1946 e a Convenção sobre Privilégios e Imunidades das Agências Especializadas das Nações Unidas de $1947 .{ }^{30}$

A imunidade jurisdicional das organizações internacionais deriva, portanto, da vontade dos Estados, a qual se manifesta por meio de tratados constitutivos, acordos bilaterais de sede e tratados multilaterais de privilégios e imunidades. Outra possível fonte para regular a relação jurídica entre a organização e determinado Estado Membro é a legislação doméstica, como ocorre, por exemplo, nos Estados Unidos, com o International Organizations Immunities Act.

Em relação a seu alcance, as imunidades concedidas às organizações internacionais podem dizer respeito à inviolabilidade de seus locais, salvo em casos de extrema urgência; à inviolabilidade de seus arquivos; a isenções de natureza financeira e fiscal; a facilidades imigratórias; e, principalmente, a não comparecer perante os tribunais nacionais - a imunidade jurisdicional. De acordo com parecer da Corte Internacional de Justiça, os privilégios e imunidades das organizações internacionais devem ser integralmente observados, inclusive pelo Estado de nacionalidade e de residência do agente em questão, no exercício de suas funções oficiais. ${ }^{31}$

A origem do estudo sobre as imunidades das organizações internacionais situa-se no período entreguerras, com a criação da primeira grande organização de natureza universal, a Liga das Nações. É interessante

\footnotetext{
30 VELASCO, Manuel Diez de. Las organizaciones internacionales. Madri: Tecnos, 2008. p. 83.

31 CORTE INTERNACIONAL DE JUSTIÇA. Application of Article VI, Section 22, of the Convention on the Privileges and Immunities of the United Nations, Advisory Opinion. I.C.J. Reports, 1989. p. 196
}

notar que as grandes questões sobre o tema, que permanecem objeto de debate acadêmico na atualidade, já haviam sido abordadas na década de 1920 pelo Institut de Droit International, à medida que surgiam os primeiros casos contra funcionários da Liga das Nações perante tribunais internos europeus.

Na sessão de Viena de 1924, membros do Institut já haviam concluído que, diferentemente dos Estados, o fundamento das imunidades das organizações internacionais residia na garantia do exercício de suas funções. Os membros do Institut haviam debatido, igualmente, o problema da denegação da justiça, quando se observou que a imunidade deveria ser renunciada sempre quando deixasse de servir ao interesse de proteger a organização. ${ }^{32}$

Debatia-se o tema, também, na União Pan-americana, durante a elaboração, em 1927, do projeto da Convenção de Havana sobre Funcionários Diplomáticos. Embora o texto final da Convenção aprovado pela VI Conferência Pan-Americana não tenha incluído disposições sobre o tema, debateram-se, em seu travaux préparatoires, as imunidades de "membros de organizações consideradas sujeitos de direito internacional, de cortes permanentes de justiça internacional e de arbitragem, bem como de comissões de investigação criadas em virtude de acordos internacionais". ${ }^{33}$

Na década seguinte, em 1936, o primeiro escrivão da Corte Permanente de Justiça Internacional — para a qual foi posteriormente eleito juiz —, Ake Hammarskjöld, apresentaria curso na Academia de Direito Internacional, intitulado "A imunidade de pessoas investidas de funções internacionais". Ao discorrer sobre a prática e o debate acadêmico da época, Ake Hammarskjöld concluiu sobre a pertinência de se estabelecer regras gerais acerca do assunto, em vez de tratamento casuístico por meio das regras específicas de cada organização. ${ }^{34}$

Poucos anos depois, com o advento das Nações Unidas, foi possível avançar na adoção de regras sobre

32 BLOKKER, Niels. International organizations: the untouchables? In: BLOKKER, Niels. Immunity of International Organizations. Leiden: Brill Nijhoff, 2015. p. 6-8.

${ }^{33}$ HAMMARSKJOLD, Ake. Les immunités des personnes investies de fonctions internationales. Recueil des cours, v. 56, 1936. p. 190. ${ }^{34}$ Cf., em particular, o capítulo IV ("La question d'une réglementation générique”). HAMMARSKJOLD, Ake. Les immunités des personnes investies de fonctions internationales. Recueil des cours, v. 56, 1936. p. 107-211. Cf., em particular, o capítulo IV ("La question d'une réglementation générique"). 
as imunidades das organizações internacionais, inspiradas nos debates acadêmicos e na prática das duas décadas anteriores. Contudo, ao contrário do que sugerira Ake Hammarskjöld, as regras passaram a ser adotadas de maneira casuística, aplicáveis separadamente a cada organização internacional. Dessa forma, foram adotadas, em 1946, a Convenção sobre Privilégios e Imunidades das Nações Unidas e, no ano seguinte, a Convenção sobre Privilégios e Imunidades das Agências Especializadas das Nações Unidas. Em que pese a diversidade de instrumentos relativos às imunidades das organizações internacionais criadas nos anos seguintes, os dispositivos sobre as Nações Unidas tiveram expressiva projeção e influenciaram o tratamento desse assunto em relação a outros organismos, razão pela qual o presente capítulo dará ênfase maior a esses dois instrumentos.

A multiplicação de novas organizações internacionais e o tratamento casuístico até então conferido às imunidades desses sujeitos levou a CDI a trabalhar sobre o tema de maneira sistemática e geral, com a inclusão, em 1963, do tópico "Relações entre Estados e organizações internacionais" em sua agenda. A decisão da CDI de incluir o tema em seus trabalhos decorreu de convite que a AGNU havia feito anos antes, em 1958, por meio da resolução 1289 (XIII). O primeiro relator, o egípcio Abdullah El-Erian, optou por dividir o tema em duas partes, abordadas em momentos distintos. Em um primeiro momento, a CDI tratou dos privilégios e das imunidades de representantes de Estados junto a organizações internacionais, o que culminou, em 1975, na Convenção de Viena sobre a Representação de Estados em suas Relações com Organizações Internacionais de Caráter Universal. ${ }^{35}$

Concluída a primeira parte do tópico, a CDI passou então a trabalhar, em 1976, em artigos sobre os privilégios e as imunidades das organizações internacionais. O Relator optou por restringir o tema apenas às organizações internacionais de natureza universal, o que foi aprovado pela CDI. Com a eleição de El-Erian para a CIJ, o novo relator do tema passou a ser o venezuelano Leonardo Díaz-González, em 1979, que preparou Projeto de Artigos sobre o tema, estruturado em três seções: (i) privilégios e imunidades das organizações —

\footnotetext{
35 O Brasil assinou a Convenção em 14 de março de 1975, mas não a ratificou. Até o momento, apenas 34 Estados ratificaram o instrumento. Concluída há mais de 40 anos, a Convenção ainda não se encontra em vigor - faltando o depósito de apenas mais um instrumento de ratificação para se atingir o número mínimo necessário.
}

estes subdivididos em fiscais e não fiscais; (ii) privilégios e imunidades de oficiais; e (iii) privilégios e imunidades de peritos em missão e de pessoas que mantêm negócios oficiais com a organização.

Díaz-González apresentou 22 artigos sobre o tema ao longo de seus quatro relatórios - no total, o assunto foi objeto de seis relatórios ao longo de duas décadas. Cabe destacar que, nesses artigos, a imunidade jurisdicional das organizações internacionais foi formulada de maneira absoluta, sem possibilidade de limitação. Essa abordagem decorria do entendimento de que correspondia à natureza absoluta da imunidade jurisdicional a obrigação das organizações internacionais de estabelecer mecanismos internos de controle, como se depreende do seguinte trecho do quarto relatório de Díaz-González:

De acordo com a maioria dos textos (convenções
sobre privilégios e imunidades, acordos de sede,
entre outros), organizações internacionais não
podem ser julgadas por tribunais nacionais a não
ser que tenham expressamente renunciado a esse
privilégio. Ainda que o tenham feito, a renúncia não
se estende às medidas de execução. Essa situação,
embora possa parecer excessiva, está limitada pela
obrigação imposta às organizações internacionais
de instituir um sistema judicial para a solução de
controvérsias ou de disputas em que possam estar
envolvidas. ${ }^{36}$

Em 1992, a CDI optou por encerrar as discussões sobre o assunto. Os motivos para essa decisão incluíam o lento processo de ratificação da Convenção de Viena sobre a Representação de Estados em suas Relações com Organizações Internacionais de Caráter Universal, o que demonstrou pouca disposição em se avançar na segunda parte do tópico "Relações entre Estados e organizações internacionais", relativa à imunidade jurisdicional das organizações internacionais; e a constatação de que numerosas questões levantadas durante os trabalhos já haviam sido regulamentadas por tratados existentes. ${ }^{37}$

${ }^{36}$ COMISSÃO DE DIREITO INTERNACIONAL. UN Doc. A/CN.4/424 and Corr.1. DÍAZ GONZÁLEZ, Leonardo. Fouth report on relations between States and international organizations (second part of the topic). In: UNITED NATIONS. Yearbook of the International Law Commission 1989. New York: UN, 1992. v. 2. p. 161. tradução nossa.

37 LAMMERS, Johan G. Immunity of international organizations: the work of the International Law Commission. In: BLOKKER, Niels. Immunity of international organizations. Leiden: Brill Nijhoff, 2015. p. 27. 
Não obstante o encerramento das discussões, em momentos posteriores sugeriu-se a retomada dos trabalhos. Giorgio Gaja, durante seu mandato na CDI, recomendou que o estudo sobre a imunidade jurisdicional das organizações internacionais fosse retomado, em vista da adoção pela AGNU da Convenção das Nações Unidas sobre Imunidade Jurisdicional dos Estados e sua Propriedade, em 2006. Todavia, a CDI não se dispôs a trabalhar em tratado similar sobre as imunidades das organizações internacionais. A variedade das organizações internacionais e a quantidade de tratados existentes sobre suas imunidades têm sido desafios significativos para as sucessivas tentativas de se adotar abordagem sistemática, válida para todos os organismos.

Atualmente, outras propostas têm surgido para conferir tratamento coerente ao tema das imunidades jurisdicionais das organizações internacionais. O Comitê Jurídico Interamericano da Organização dos Estados Americanos, em seu $93^{\circ}$ período ordinário de sessões, em agosto de 2018, aprovou o documento “Guia Prático de Aplicação da Imunidade Jurisdicional das Organizações Internacionais". O objetivo do guia é recomendar aos Estados Membros da OEA boas práticas e elementos que poderiam ser incorporados em futuros acordos de sede e nas legislações nacionais, para prevenir possíveis controvérsias e oferecer meios para sua resolução. A elaboração do guia decorreu da constatação de que a imunidade das organizações internacionais tem recebido tratamento casuístico no continente americano, em razão tanto dos distintos tratados constitutivos e acordos de sede existentes quanto das diferentes decisões de tribunais nacionais em 18 Estados Membros da OEA. ${ }^{38}$

O guia da OEA pode servir para Estados e organizações internacionais para uma melhor condução de suas relações jurídicas. Além disso, tribunais nacionais podem tomar o documento como subsídio para a elaboração de suas decisões, conferindo coerência à jurisprudência na região. O documento apresenta dez diretrizes gerais, que incluem tópicos como base jurí-

\footnotetext{
38 ORGANIZAÇÃO DOS ESTADOS AMERICANOS. Imunidade das organizações internacionais. CJI/Res. 241 (XCIII-O/18), de 10 de agosto de 2018. Anexo à resolução consta o relatório do Comitê Jurídico Interamericano, que cita lista de decisões de tribunais nacionais de 18 Estados Membros da OEA, a saber: Argentina, Bolívia, Canadá, Chile, Colômbia, Costa Rica, Equador, El Salvador, Estados Unidos da América, Guatemala, México, Panamá, Paraguai, Peru, República Dominicana, Trinidad e Tobago, Uruguai e Venezuela.
}

dica da imunidade jurisdicional das organizações internacionais; objetivo, alcance e limites das imunidades; meios de solução de controvérsias; relação com o ordenamento jurídico interno e tribunais domésticos; imunidade de execução; e renúncia às imunidades. Trata-se de abordagem distinta à da CDI que, embora careça de natureza vinculante, pode favorecer o desenvolvimento de uma prática regional coerente e equilibrada no que se refere à aplicação, interpretação e eventual limitação da imunidade jurisdicional das organizações internacionais. Além disso, pode servir como referência não apenas aos tribunais nacionais, mas também para a negociação de futuros acordos constitutivos ou de sede que incluam dispositivos sobre privilégios e imunidades. ${ }^{39}$

Interessante notar que o Comitê Jurídico Interamericano apontou para a inexistência, no continente americano, de tratamento homogêneo relativo às imunidades das organizações internacionais, diante das distintas práticas de órgãos administrativos e judiciais e do fato de que a maioria dos Estados Membros da OEA ainda carece de legislação nacional sobre o tema. Nesse contexto, o Comitê concluiu que não existem condições para que a OEA considere a elaboração de instrumento internacional juridicamente vinculante sobre as imunidades das organizações internacionais. ${ }^{40}$

Niels Blokker sugere que o atual sistema normativo que regulamenta as imunidades das organizações internacionais ancora-se na prática e no pensamento das décadas de 1920 e 1930, pouco tendo mudado ao longo dos anos. Ao analisar as imunidades de organizações internacionais criadas a partir dos anos 2000, Blokker conclui que há significativa semelhança com o tratamento dado pelas Convenções das Nações Unidas de 1946 e de $1947 .{ }^{41}$ Conquanto haja rigidez no sistema normativo, verifica-se que o debate acadêmico sobre o assunto tem-se transformado, em particular quanto à aplicabilidade de imunidades de organizações internacionais frente ao Direito Internacional dos Direitos Humanos. A prática também tem dado sinais de mudanças, com o número maior de ajuizamento de ações

\footnotetext{
39 ORGANIZAÇÃO DOS ESTADOS AMERICANOS. Imunidade das organizações internacionais. CJI/Res. 241 (XCIII-O/18), de 10 de agosto de 2018.

40 ORGANIZAÇÃO DOS ESTADOS AMERICANOS. Imunidade das organizações internacionais. CJI/Res. 241 (XCIII-O/18), de 10 de agosto de 2018. p. 11.

41 BLOKKER, Niels. International organizations: the untouchables? In: BLOKKER, Niels. Immunity of International Organizations. Leiden: Brill Nijhoff, 2015. p. 11-15.
} 
contra essas organizações em tribunais domésticos, em casos de violações de direitos humanos — não mais se restringindo apenas a questões trabalhistas.

Dificilmente haverá mudanças significativas no arcabouço normativo geral que rege as imunidades das organizações internacionais. Por isso, deve-se buscar melhorar a implementação das regras já existentes, sobretudo nos casos que envolvem violações de direitos humanos. O paradigma funcionalista pode ser aplicado não apenas como fundamento dessas imunidades, mas também como garantia de que as organizações internacionais sigam as normas internacionais. ${ }^{42}$

\section{Os limites da imunidade jurisdicional das organizações internacionais}

A imunidade jurisdicional é conferida às organizações internacionais para assegurar que estas possam realizar os propósitos e os objetivos pactuados por seus Estados Membros. Seguindo esse entendimento funcionalista, as organizações internacionais devem carecer de imunidade jurisdicional em três situações: (i) quando optam por renunciá-la; (ii) quando atuam como agentes exclusivamente privados, incluindo em disputas trabalhistas que não comprometem sua autonomia; e (iii) quando não oferecem meios alternativos de solução de controvérsias, em violação do direito de acesso à justiça.

\subsection{Renúncia às imunidades jurisdicionais}

Embora o tratamento que as organizações internacionais conferem às imunidades jurisdicionais possa variar, o caso das Nações Unidas é ilustrativo por haver inspirado diversos instrumentos constitutivos surgidos ao longo do século XX. Nesse contexto, caberia destacar, inicialmente, o artigo 105(1) da Carta das Nações Unidas, que limita os privilégios e imunidades da Organização ao "exercício de suas funções e à realização de seus propósitos", em conformidade com o paradigma do funcionalismo.

\footnotetext{
42 BLOKKER, Niels. International organizations: the untouchables? In: BLOKKER, Niels. Immunity of International Organizations. Leiden: Brill Nijhoff, 2015. p. 17.
}

Ainda que a limitação aos privilégios e às imunidades tenha sido formulada de maneira expressa na Carta da ONU, a questão foi posteriormente regulamentada de maneira mais restritiva pela Convenção sobre Privilégios e Imunidades das Nações Unidas de 1946, que apresenta a renúncia como única hipótese de limitação à imunidade jurisdicional em um caso concreto. ${ }^{43}$ A Convenção sobre Privilégios e Imunidades das Agências Especializadas das Nações Unidas de 1947 reproduziu, em seu artigo $3^{\circ}$, seção 4, o disposto na Convenção de 1946 para todas as agências, programas e fundos do sistema das Nações Unidas. ${ }^{44}$

Essas limitações aparentemente mínimas às imunidades e privilégios das organizações internacionais devem ser lidas, no entanto, à luz do artigo 105(1) da Carta, que toma como fundamento para as imunidades o paradigma funcionalista. Além disso, devem ser lidas também à luz da obrigação imposta ao SGNU pelo artigo $5^{\circ}$, seção 20, da Convenção de 1946. Esse dispositivo impõe ao SGNU o poder e o dever de suspender as imunidades dos funcionários das Nações Unidas sempre que possam impedir a aplicação da justiça, desde que não cause prejuízo aos interesses da Organização, como se pode depreender a seguir:

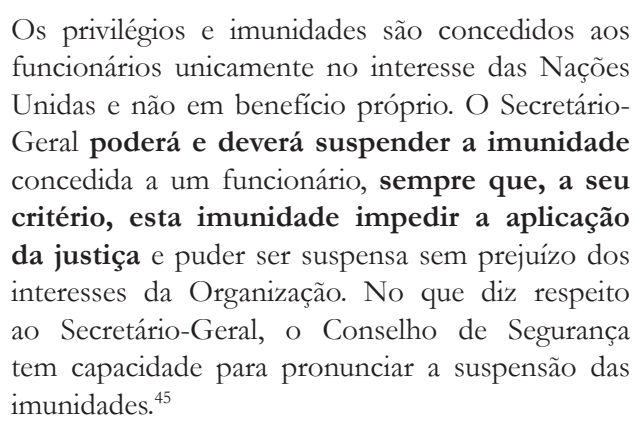

${ }^{43}$ NAÇÕES UNIDAS. Convenção sobre Privilégios e Imunidades das Nações Unidas, artigo 2, seção 2: "A Organização das Nações Unidas, seus bens e haveres, qualquer que seja sua sede ou o seu detentor, gozarão da imunidade de jurisdição, salvo na medida em que a Organização a ela tiver renunciado em determinado caso. Fica, todavia, entendido que a renúncia não pode compreender medidas executivas".

${ }^{44}$ NAÇÕES UNIDAS. Convenção sobre Privilégios e Imunidades das Agências Especializadas das Nações Unidas, artigo $3^{\circ}$, seção 4: "As agências especializadas, seus bens e ativo, onde estiverem localizados e qualquer que seja o seu depositário, gozarão de imunidade de todas as formas de processo legal, exceto na medida em que, em qualquer caso determinado houverem expressamente renunciado à sua imunidade. Fica entendido, porém, que nenhuma renúncia de imunidade se estenderá a qualquer medida de execução".

45 NAÇÕES UNIDAS. Convenção sobre Privilégios e Imunidades das Nações Unidas, artigo $5^{\circ}$, seção 20, grifo nosso. 
Cumpre notar que a fórmula utilizada pelo artigo $5^{\circ}$, seção 20, da Convenção de 1946, em relação aos funcionários das Nações Unidas, é reproduzida no artigo $6^{\circ}$, seção 23 , ao tratar dos peritos em missão pela Organização. No caso das Nações Unidas, pode-se concluir que são dois os limites para sua imunidade jurisdicional: (i) esta deve dar-se no exercício de suas funções e na realização de seus propósitos; e (ii) não deve impedir a aplicação da justiça, desde que sua suspensão não cause prejuízo aos interesses da Organização — avaliação subjetiva que cabe ao SGNU.

Cabe destacar a interpretação realizada pela Corte Internacional de Justiça do artigo $5^{\circ}$, seção 20, da Convenção de 1946. Em Opinião Consultiva a respeito da inobservância da imunidade de agente das Nações Unidas por um Estado Membro, a CIJ esclareceu que cabe ao SGNU o poder e o dever de decidir sobre a renúncia da imunidade de funcionários das Nações Unidas. Essa decisão implica qualificar, igualmente, se $\mathrm{o}$ ato desse agente teria ocorrido no exercício de suas funções oficiais. Nesse contexto, a Corte acrescentou que é responsabilidade do SGNU informar ao Estado em questão sobre a imunidade do agente, para que os tribunais nacionais sejam devidamente comunicados. A responsabilidade passa então a ser do Estado Membro de notificar os tribunais nacionais sobre a imunidade jurisdicional do agente. ${ }^{46}$

Além das Nações Unidas, o tratamento que outras organizações internacionais conferem à imunidade jurisdicional parece variar pouco. Em geral, nos casos em que a renúncia é permitida, esta deve ser realizada pelo titular da organização em questão, tanto em relação à imunidade de jurisdição quanto à imunidade de execução. Essa renúncia deve dar-se de acordo com os regimes jurídicos de cada organização internacional. Nesse sentido, a renúncia pode ser estritamente voluntária ou, como no caso das Nações Unidas, pode decorrer de uma obrigação - como o não impedimento à aplicação da justiça. Por fim, cabe destacar que a renúncia à imunidade jurisdicional não compreende ipso facto a renúncia à imunidade de execução.

${ }^{46}$ CORTE INTERNACIONAL DE JUSTIÇA. Differences relating to immunity from legal process of a Special Rapporteur of the Commission on Human Rights, Advisory Opinion. I.C.J. Reports, 1999. p. 87.

\subsection{Limitação da imunidade para atos não oficiais}

A imunidade jurisdicional das organizações internacionais, ao se fundamentar na noção do funcionalismo, deveria ser aplicável apenas às atividades consideradas essenciais e necessárias aos propósitos e objetivos desses organismos. Corolário desse entendimento seria a renúncia à imunidade para atos em que as organizações internacionais participam como agentes privados, incluindo disputas trabalhistas que não comprometam a autonomia da organização. No entanto, caso a renúncia não seja realizada nesses casos, alguns tribunais domésticos têm entendido ser necessário avaliar, caso a caso, a natureza dos atos em questão, para avaliar se estariam excluídos da imunidade jurisdicional.

Nessa avaliação, é recorrente o recurso à analogia inadequada com a imunidade jurisdicional dos Estados, mediante a aplicação dos conceitos de iure gestionis (atos de gestão) e iure imperii (atos de império). No entanto, cabe frisar que as organizações internacionais não praticam atos de império ou de gestão. Como aponta Leandro Moll, a classificação mais apropriada consistiria em atos oficiais, intrínsecos às suas funções e objetivos consagrados em tratados constitutivos, e atos não oficiais. ${ }^{47}$

A título de ilustração, a contratação de intérprete pode ser considerada, para um Estado estrangeiro, como um ato de gestão, enquanto que, para determinada organização internacional, pode ser classificada como ato funcional, caso se mostre como elemento de funcionalidade do organismo. Verifica-se, portanto, a impossibilidade de transposição automática dos conceitos de atos de império e atos de gestão para o domínio das imunidades das organizações internacionais. ${ }^{48}$

Em suma, as organizações internacionais deveriam renunciar às imunidades sempre quando atuam como agentes exclusivamente privados em atividades alheias a seus propósitos e objetivos. Caso a renúncia não seja realizada, a distinção entre atos oficiais e atos não oficiais poderia servir aos tribunais como instrumento de avaliação da natureza do ato em questão. Caso se trate de ato não oficial, a imunidade poderia ser relativizada, e

\footnotetext{
47 MOLL, Leandro de Oliveira. Imunidades internacionais: tribunais nacionais ante a realidade das organizações internacionais. Brasília: FUNAG, 2010. p. 101.

48 MOLL, Leandro de Oliveira. Imunidades internacionais: tribunais nacionais ante a realidade das organizações internacionais. Brasília: FUNAG, 2010. p. 102.
} 
a controvérsia, dirimida pelos tribunais domésticos. Por sua vez, caso se trate de ato oficial, a imunidade jurisdicional deve ser aplicada, e a própria organização deve oferecer mecanismos internos de solução de controvérsias, como imperativo do direito de acesso à justiça.

\subsection{A obrigação de oferecer meios de solução de controvérsias e 0 abuso de imunidade}

Se a organização internacional não renunciar a suas imunidades jurisdicionais, esta deve oferecer meios de solução de controvérsias apropriados, conforme disposto na seção 29 da Convenção de 1946 e na seção 31 da Convenção de 1947. ${ }^{49}$ Ambas as seções preveem que esses meios devem ser estabelecidos para as controvérsias em matéria de contratos ou de natureza privada, bem como para disputas que envolvam funcionários que não tenham tido suas imunidades dispensadas.

A obrigação de oferecer meios de solução de controvérsias foi incluída em ambas as Convenções como forma de coadunar as imunidades jurisdicionais com o direito de acesso à justiça. Cabe recordar que Díaz-González, em seu trabalho na CDI, havia condicionado a natureza absoluta da imunidade jurisdicional das organizações internacionais à obrigação de instituir sistemas internos de solução de controvérsias.

Contudo, conforme verificado no capítulo anterior, poucos mecanismos internos de controle foram desenvolvidos pelas organizações internacionais até o momento. Os tribunais administrativos poderiam cumprir parcialmente esse papel, mas se restringem a questões trabalhistas envolvendo funcionários. Contratados locais em regime temporário ou terceiros, por exemplo, estão impossibilitados de recorrer a esses tribunais. A

\footnotetext{
49 NAÇÕES UNIDAS. Convenção sobre Privilégios e Imunidades das Nações Unidas, artigo $8^{\circ}$, seção 29: “A Organização das Nações Unidas deverá estabelecer processos adequados de solução para: (a) as controvérsias em matéria de contratos ou outras de direito privado nas quais a Organização seja parte; (b) as controvérsias nas quais estiver implicado um funcionário da Organização que, em virtude de sua situação oficial gozar de imunidade que não tenha sido suspensa pelo Secretário Geral". Cf. também Convenção sobre Privilégios e Imunidades das Agências Especializadas das Nações Unidas, artigo $9^{\circ}$, seção 31: "Cada agência especializada providenciará modos apropriados de resolver: (a) disputas resultantes de contratos ou outras disputas de caráter privado nas quais a agência especializada seja parte; (b) disputas que envolvam qualquer funcionário de uma agência especializada que, por motivo de sua posição oficial, goze de imunidade, se a imunidade não houver sido dispensada, de conformidade com as disposições da $22^{\mathrm{a}}$ Seção.
}

situação agrava-se, ainda mais, em casos que transcendem o escopo privatista e envolvem violações de direitos humanos, para os quais há poucos recursos internos disponíveis.

Em uma leitura desatenta, a previsão de que toda divergência referente à interpretação ou à aplicação das Convenções de 1946 e de 1947 deve ser submetida à CIJ, - presente nas seções 29 e 32, respectivamente poderia parecer uma possível solução para os casos em que se busca instituir limites à imunidade jurisdicional das Nações Unidas. Contudo, esse recurso encontra-se disponível apenas aos Estados, ainda que a prática internacional tenha demonstrado que são os indivíduos os principais prejudicados por atos ilícitos cometidos por organizações internacionais.

No caso da Convenção de 1947, em particular, é interessante destacar a incorporação da figura do abuso de privilégios e imunidades. $\mathrm{O}$ artigo $7^{\circ}$, seção 24 , da Convenção de 1947, prevê que, se qualquer país considerar que houve abuso de um privilégio ou imunidade, deverão ser realizadas consultas diretas entre as autoridades estatais e a agência especializada em questão, com vistas a determinar se ocorreu abuso e, nesse caso, assegurar sua não repetição. Se as consultas não alcançarem resultado satisfatório para o Estado e a agência especializada interessados, a questão poderá ser submetida à CIJ. Se a Corte determinar que houve abuso, o país poderá retirar da agência especializada os benefícios do privilégio ou da imunidade objeto do abuso. Trata-se de recurso disponível apenas aos Estados. Não obstante, esse dispositivo torna questionável a aplicação de maneira absoluta da imunidade jurisdicional das agências especializadas das Nações Unidas, sem prévia análise da natureza oficial do ato em questão e da possível ocorrência de abusos.

Também o Acordo sobre Privilégios e Imunidades da Organização dos Estados Americanos prevê a possibilidade de abuso de imunidade e institui a obrigação de cooperar com as autoridades estatais. Com efeito, o artigo 11 do Acordo estabelece que a OEA cooperará com as autoridades competentes para facilitar a administração adequada da justiça e evitar que se verifiquem abusos com relação aos privilégios e imunidades da organização.

A renúncia, nos casos em que as imunidades jurisdicionais possam impedir a aplicação da justiça, pode ser interpretada como um corolário da obrigação de coope- 
rar com as autoridades competentes dos Estados Membros. Além disso, em casos relativos a atos não oficiais, a renúncia pode até mesmo assegurar a natureza funcional das imunidades da organização. Caso a renúncia não seja realizada, os tribunais domésticos poderiam lançar mão de análise sobre a natureza oficial ou não oficial do ato em questão. Ademais, a não realização da renúncia obriga a organização internacional a oferecer meios de solução de controvérsias aos interessados.

Não obstante previsões normativas sobre o poder-dever de renúncia, como no artigo $5^{\circ}$, seção 20 , da Convenção de 1946, as organizações internacionais não costumam renunciar à imunidade jurisdicional, o que tem impedido o desenvolvimento da prática de responsabilização desses sujeitos. Além disso, conforme demonstrado no capítulo anterior, ainda não se desenvolveram satisfatoriamente mecanismos internos de controle capazes de oferecer meios de solução de controvérsias adequados. Para agravar a situação, diversos tribunais domésticos continuam a aplicar as imunidades das organizações internacionais de maneira absoluta. Como reação, a academia e a jurisprudência de tribunais regionais e internos têm proposto alternativas que levam à relativização da imunidade das organizações internacionais em casos de flagrante denegação do direito de acesso à justiça.

\section{A imunidade de jurisdição das organizações internacionais e o direito de acesso à justiça}

A denegação de justiça tornou-se o principal problema em relação à imunidade jurisdicional das organizações internacionais. Esse problema agrava-se sobremaneira no caso de violações do direito internacional geral e de normas de jus cogens. No caso dos Estados, potencial denegação de justiça decorrente da imunidade jurisdicional poderia ser contornada mediante ajuizamento de ação no território nacional, como foro alternativo. Afinal, o Estado nacional e os agentes diplomáticos não estarão imunes à sua própria jurisdição nacional. Já em relação às organizações internacionais, na maioria dos casos não há mecanismos de controle interno disponíveis ou efetivos a que se possa recorrer.

O problema da denegação de justiça é enfrentado pelo Direito Internacional Público por meio de diversos tratados de direitos humanos que consagram o direito às garantias judiciais, tanto de escopo regional quanto universal. A título de exemplo, destacam-se o artigo 14(1) do Pacto Internacional sobre Direitos Civis e Políticos de 1966 e o artigo 8(1) da Convenção Americana sobre Direitos Humanos. ${ }^{50}$ Entende-se por garantias judiciais, inter alia, o direito a comparecer perante tribunal competente, independente e imparcial, estabelecido anteriormente por lei, para determinação dos direitos e das obrigações de qualquer natureza das partes no processo.

Cumpre notar que o direito às garantias judiciais foi alçado à categoria de norma de jus cogens pela jurisprudência da Corte Interamericana de Direitos Humanos. Com efeito, no caso Goiburú e outros v. Paraguai, a Corte reconheceu que o acesso à justiça constitui norma imperativa de Direito Internacional e gera, portanto, obrigações erga omnes para que os Estados adotem as medidas necessárias para impedir a impunidade, seja pelo exercício de sua jurisdição para a aplicação de seu direito doméstico seja pela cooperação com outros Estados. ${ }^{51}$

${ }^{50}$ Cf. Pacto Internacional sobre Direitos Civis e Políticos, artigo 14(1): "todas as pessoas são iguais perante os tribunais e as cortes de justiça. Toda pessoa terá o direito de ser ouvida publicamente e com devidas garantias por um tribunal competente, independente e imparcial, estabelecido por lei, na apuração de qualquer acusação de caráter penal formulada contra ela ou na determinação de seus direitos e obrigações de caráter civil. A imprensa e o público poderão ser excluídos de parte da totalidade de um julgamento, quer por motivo de moral pública, de ordem pública ou de segurança nacional em uma sociedade democrática, quer quando o interesse da vida privada das Partes o exija, que na medida em que isso seja estritamente necessário na opinião da justiça, em circunstâncias específicas, nas quais a publicidade venha a prejudicar os interesses da justiça; entretanto, qualquer sentença proferida em matéria penal ou civil deverá torna-se pública, a menos que o interesse de menores exija procedimento oposto, ou processo diga respeito à controvérsia matrimoniais ou à tutela de menores", grifo nosso. $C f$. igualmente a Convenção Americana sobre Direitos Humanos, artigo $8^{\circ}(1)$ : "toda pessoa tem direito a ser ouvida, com as devidas garantias e dentro de um prazo razoável, por um juiz ou tribunal competente, independente e imparcial, estabelecido anteriormente por lei, na apuração de qualquer acusação penal formulada contra ela, ou para que se determinem seus direitos ou obrigações de natureza civil, trabalhista, fiscal ou de qualquer outra natureza". Ver também o artigo 10 da Declaração Universal sobre Direitos Humanos; e o artigo 6(1) da Convenção Europeia sobre Direitos Humanos.

51 "El acceso a la justicia constituye una norma imperativa de Derecho Internacional y, como tal, genera obligaciones erga omnes para los Estados de adoptar las medidas que sean necesarias para no dejar en la impunidad esas violaciones, ya sea ejerciendo su jurisdicción para aplicar su derecho interno y el derecho internacional para juzgar y, en su caso, sancionar a los responsables, o colaborando con otros Estados que lo hagan o procuren hacerlo". CORTE INTER- 
Diante da possibilidade de impunidade em relação a violações de direitos humanos, é importante interpretar e aplicar o paradigma funcionalista à luz de outras obrigações decorrentes do Direito Internacional Público, de maneira sistêmica e não isolada. Em particular, cabe buscar convergência entre dois objetivos da ordem pública internacional: de um lado, a garantia de que as organizações internacionais serão resguardadas contra interferências unilaterais de governos; de outro, a proteção internacional dos direitos humanos.

Deve-se não apenas evitar que a imunidade jurisdicional das organizações internacionais sirva como pretexto para a violação de direitos fundamentais e normas de Direito Internacional dos Direitos Humanos, mas assegurar que ambos os regimes normativos se apoiem e reforcem mutuamente. O entendimento de que a imunidade jurisdicional das organizações internacionais deve depender de certos critérios, como a disponibilidade e efetividade de mecanismos alternativos de solução de controvérsias, é um possível caminho a promover sinergias entre ambos os regimes. A Corte Europeia de Direitos Humanos e alguns tribunais domésticos têm adotado esse entendimento.

No caso da imunidade jurisdicional gozada pelos Estados, há possibilidade de compor a lide na jurisdição doméstica do próprio Estado reclamado, como alternativa à aplicação da imunidade em território estrangeiro. Dependendo das circunstâncias de cada caso, pode-se questionar se essa alternativa seria razoável ou mesmo efetiva para o reclamante. Todavia, a mera existência dessa possibilidade demonstra que o direito de acesso à justiça pode ser exercido em foros distintos, não exclusivamente na jurisdição onde ocorreu a violação. No caso das organizações internacionais, muitas vezes essa possibilidade não existe ou é claramente inefetiva. A aplicação da imunidade jurisdicional a uma organização internacional que não disponha de mecanismos internos de solução de controvérsias poderá implicar violação do direito às garantias judiciais da parte demandante.

Cabe destacar que a necessidade de instituir mecanismos de solução de controvérsias não decorre tão somente da garantia do direito de acesso à justiça. Decorre, igualmente, de instrumentos constitutivos das próprias organizações internacionais, de tratados mul-

AMERICANA DE DIREITOS HUMANOS. Caso Goiburú e outros v. Paraguai. Mérito, reparações e custas (Série C No. 153). Julgamento de 22 de setembro de 2006. tilaterais sobre privilégios e imunidades - como é o caso da Convenção sobre Privilégios e Imunidades das Nações Unidas — e de acordos bilaterais de sede. Além disso, a jurisprudência recente de tribunais internacionais e domésticos tem afirmado a obrigação direta das organizações internacionais de proverem mecanismos adequados de solução de controvérsias como pré-condição para o gozo de seus privilégios e imunidades. ${ }^{52}$

\subsection{A jurisprudência de tribunais regionais e domésticos e a relativização da imunidade jurisdicional das organizações internacionais}

A Corte Europeia de Direitos Humanos, no caso Waite e Kennedy vs. Alemanha, estabeleceu que a imunidade jurisdicional pode depender da disponibilidade de garantias judiciais adequadas e efetivas. Trata-se de caso paradigmático que tem servido de referência também para decisões de tribunais domésticos. Nesse caso, a CEDH estabeleceu três requisitos básicos como condição para a aplicação da imunidade jurisdicional de uma organização internacional, a saber: (i) eventuais limitações ao acesso à justiça não devem implicar redução nem do escopo nem da essência desse direito; (ii) as limitações à imunidade devem buscar alcançar um objetivo legítimo; e (iii) deve haver relação de razoável proporcionalidade entre os meios aplicados e o objetivo logrado. ${ }^{53}$

Em Waite vs. Kennedy, a CEDH destacou que a proteção das organizações internacionais contra ingerências de Estados por meio da imunidade jurisdicional constitui objetivo legítimo para limitação do direito de acesso à justiça. ${ }^{54}$ Além disso, verificou que a organização internacional em questão, a Agência Espacial Europeia, dispunha de mecanismos internos de solução de controvérsias e oferecia alternativas aos demandantes, razão pela qual não haveria desproporcionalidade nem limitação do escopo e da essência do direito de acesso à

${ }_{52}$ REINISCH, August; WEBER, Ulf Andreas. In the shadow of Waite and Kennedy: the jurisdictional immunity of international organizations, the individual's right of access to the courts and administrative tribunals as alternative means of dispute settlement. International Organizations Law Review, n. 1, 2004. p. 68.

53 CORTE EUROPEIA DE DIREITOS HUMANOS. Waite and Kennedy vs. Alemanha. Application n. 26083/94. Judgment, 18 February 1999. p. 13.

${ }^{54}$ CORTE EUROPEIA DE DIREITOS HUMANOS. Waite and Kennedy vs. Alemanha. Application no. 26083/94. Judgment, 18 February 1999. p. 14. 
justiça, conforme previsto no artigo 6(1) da Convenção Europeia de Direitos Humanos. ${ }^{55} \mathrm{Em}$ Beer and Regan vs. Alemanha, a $\mathrm{CEDH}$ indicou, igualmente, que a imunidade jurisdicional de organizações internacionais pode resultar em eventuais violações do direito de acesso à justiça, caso sua aplicação não seja mitigada pela disponibilidade de meios alternativos de solução de controvérsias. ${ }^{56}$

Embora a jurisprudência da CEDH tenha se tornado referência para casos sobre conflitos entre a aplicação de imunidades e a salvaguarda de direitos humanos, cumpre notar que a Corte Internacional de Justiça optou por abordagem diametralmente oposta. No caso Alemanha vs. Itália, a imunidade jurisdicional da Alemanha foi aplicada, ainda que diante de crimes de guerra para os quais não havia mecanismos de solução de controvérsias disponíveis. Defrontada com o argumento de que normas de jus cogens deveriam prevalecer sobre a imunidade jurisdicional dos Estados, a CIJ declarou se tratar de âmbitos distintos de aplicação, uma vez que as imunidades teriam natureza meramente procedimental, não substantiva. ${ }^{57}$ Segundo alguns autores, a CEDH teria adotado entendimento similar no caso Stichting Mothers of Srebrenica vs. Países Baixos, o que poderá relativizar, futuramente, o precedente firmado em Waite and Kennedy. ${ }^{58}$

Importante notar que a exigência de mecanismos alternativos para a proteção dos direitos fundamentais no contexto das organizações internacionais foi avançada, igualmente, por tribunais domésticos. O caso Solange, na Corte Constitucional Alemã, analisado no capítulo anterior, ilustra esse entendimento, posteriormente seguido também por outros tribunais, como a Corte Constitucional Italiana, no caso Frontini. ${ }^{59}$

\footnotetext{
55 CORTE EUROPEIA DE DIREITOS HUMANOS. Waite and Kennedy vs. Alemanha. Application no. 26083/94. Judgment, 18 February 1999. p. 16.

56 CORTE EUROPEIA DE DIREITOS HUMANOS. Beer and Regan vs. Alemanha, Application no. 28934/95. Judgment, 18 de fevereiro de 1999.

57 CORTE INTERNACIONAL DE JUSTIÇA. Jurisdictional immunities of the State (Germany v. Italy: Greece intervening), Judgment. ICJ Reports, 2012.

58 CORTE EUROPEIA DE DIREITOS HUMANOS. Stichting Mothers of Srebrenica v. Países Baixos. Application No. 65542/12, 11 de junho de 2013.

59 REINISCH, August; WEBER, Ulf Andreas. In the shadow of Waite and Kennedy: the jurisdictional immunity of international organizations, the individual's right of access to the courts and administrative tribunals as alternative means of dispute settlement. International Organizations Law Review, n. 1, 2004. p. 74-75.
}

A prática dos tribunais internos tem convergido para o entendimento de que toda e qualquer imunidade das organizações internacionais deve ser prevista previamente em ato internacional, seja em instrumento multilateral entre os Estados Membros seja em acordo de sede entre a organização e o Estado que a sedia. No entanto, quando se trata de limitações à imunidade jurisdicional, a prática tem variado sobremaneira. Alguns países, como o Brasil, a Áustria, os Países Baixos e o Reino Unido têm reconhecido essa imunidade de maneira absoluta. O Supremo Tribunal Federal consolidou jurisprudência no sentido de que a imunidade das organizações internacionais se aplica até mesmo a questões trabalhistas - ponto que será explorado na subseção seguinte. Outros países, no entanto, têm relativizado essa imunidade, como Bélgica, Estados Unidos, França e Itália. As contribuições jurisprudenciais de tribunais internos demonstram que há ausência de consistência na relativização da imunidade jurisdicional, o que constitui mais um óbice à responsabilização das organizações internacionais.

Na Itália, há ampla jurisprudência nos tribunais internos no sentido de relativizar a imunidade jurisdicional das organizações internacionais. Para tanto, desde a década de 1970, esses tribunais têm recorrido a analogias referentes à relativização da imunidade dos Estados, por meio da diferenciação entre atos de gestão e atos de império. ${ }^{60}$ Essas analogias, no entanto, parecem ter sido abandonadas, mais recentemente, em 2007, pela Corte Suprema Italiana. ${ }^{61}$ Não obstante esse método inadequado, em certos casos relativos à Organização das Nações Unidas para Agricultura e Alimentação (FAO), cuja sede situa-se em Roma, a Corte Suprema Italiana optou por condicionar sua imunidade à existência de mecanismos internos de solução de controvérsias. Isso implicou apreciação da estrutura institucional da organização e de sua capacidade de garantir a efetividade do artigo 24 da Constituição Italiana, que consagra o direito individual a garantias judiciais. ${ }^{62}$

\footnotetext{
60 MOLL, Leandro de Oliveira. Imunidades internacionais: tribunais nacionais ante a realidade das organizações internacionais. Brasília: FUNAG, 2010. p. 100-103.

61 BONAFÈ, Beatrice I. Italian courts and the immunity of international organizations. In: BLOKKER, Niels. Immunity of International Organizations. Leiden: Brill Nijhoff, 2015. p. 255.

62 ITÁLIA. Corte Suprema Italiana. FAOv. INPDAI, 18 de outubro de 1982; ITÁLIA. Corte Suprema Italiana. FAO v. Calagrossi, 18 de maio de 1992, No. 5942. Ver também CORTE DI CASSAZIONE. Drago vs. International Plant Genetic Resources Institute, No. 3718/2007; CORTE DI CASSAZIONE. European University Institute vs. Piette,
} 
Tribunais nos Estados Unidos também demonstraram preocupação com a falta de mecanismos de soluções de controvérsias alternativos decorrente da aplicação da imunidade jurisdicional de organizações internacionais. Em Urban vs. United Nations, o Tribunal de Apelações do Distrito de Columbia reconheceu a importância de se preservar o direito constitucional de acesso à justiça. ${ }^{63}$ O caso dos Estados Unidos é particular. O país é sede de organizações internacionais robustas, como as $\mathrm{Na}$ ções Unidas e a Organização dos Estados Americanos. Além disso, em vez de ratificar instrumentos multilaterais sobre imunidades das organizações internacionais, o país optou por aprovar lei interna sobre o assunto, em 1947, intitulada International Organization Immunities Act, a qual serviu como fundamento para a celebração de acordos de sede.

$\mathrm{Na}$ Alemanha, à luz do precedente Solange, a Corte Constitucional Federal já foi levada a analisar os procedimentos, a disponibilidade e a efetividade de mecanismos internos de solução de controvérsias de organizações internacionais ao decidir sobre sua imunidade jurisdicional. O caso Eurocontrol II é emblemático, porquanto a Corte examinou a estrutura do Tribunal Administrativo da OIT e comparou seus procedimentos com aqueles existentes no âmbito interno. ${ }^{64}$

$\mathrm{Na}$ Bélgica, há, também, jurisprudência no sentido de denegar a imunidade jurisdicional de organizações internacionais nos casos em que seus mecanismos internos de solução de controvérsias não são suficientes e tampouco compatíveis com o devido processo. Em Siedler vs. Western European Union, recorreu-se aos padrões de proteção estabelecidos pela Convenção Europeia de Direitos Humanos e pelo Pacto Internacional de Direitos Civis e Políticos para determinar que os mecanismos internos de solução de controvérsias da União da Europa Ocidental (UEO) não estavam em conformidade com normas básicas, como o direito a uma audiência pública, o direito de recorrer de decisão primária. ${ }^{65} \mathrm{Em}$ alguns casos trabalhistas até mesmo a imunidade de execução de organizações internacionais já foi relativiza-

No. $149 / 1999$.

${ }^{63}$ ESTADOS UNIDOS DA AMÉRICA. Urban vs. United Nations, D.C. Court of Appeals, 1985.

${ }^{64}$ ALEMANHA. Hetzel v. EUROCONTROL, Federal Constitutional Court, Second Chamber, 10 de novembro de 1981.

${ }^{65}$ BÉLGICA. Western European Union v Siedler, Appeal judgment, Case No S 040129 F, ILDC 1625 (BE 2009), 21 de dezembro de 2009, Court of Cassation. da. ${ }^{66} \mathrm{O}$ fundamento na aplicação da Convenção Europeia de Direitos Humanos para relativizar a imunidade jurisdicional de organizações internacionais também foi usado na França, no caso UNESCO vs. Boulois. ${ }^{67}$

Os casos citados acima são ilustrativos da tendência em certos tribunais internos de condicionar a imunidade jurisdicional de organizações internacionais à existência de outros mecanismos de solução de controvérsias, com vistas a assegurar o direito de acesso à justiça. Trata-se de lista não exaustiva de casos, muitos dos quais baseados em estudo comparativo de August Reinisch que demonstrou a variedade de demandas contra organizações internacionais que têm sido tratadas em tribunais domésticos. Segundo Reinisch, há clara tendência de contestar a imunidade jurisdicional nos casos em que sua aplicação pode levar à completa denegação de justiça a indivíduos, em razão da inexistência de mecanismos alternativos de solução de controvérsias. ${ }^{68}$ Contudo, longe de ser uma tendência global, a relativização da imunidade jurisdicional das organizações internacionais parece ser prática ainda circunscrita a alguns países do continente europeu.

\subsection{A jurisprudência brasileira e a aplicação da imunidade jurisdicional absoluta das organizações internacionais}

Alguns tribunais domésticos têm enfatizado o direito de acesso à justiça e de garantias judiciais em casos relacionados à imunidade jurisdicional das organizações internacionais. Contudo, esta não é uma tendência majoritária entre as jurisdições nacionais. O Brasil, por exemplo, tem aplicado a imunidade jurisdicional das organizações internacionais de maneira absoluta, inclusive em matéria trabalhista que envolva funcionários de secretariados, contratados locais e peritos e consultores, ainda que contratados temporariamente, sem vínculo empregatício formal.

A jurisprudência do Supremo Tribunal Federal consolidou-se nesse sentido em 2013, no caso João Batista

\footnotetext{
66 BÉLGICA. Lutchmaya vs. ACP Secretariat. Cour d'appel, Bruxelas, 4 de março de 2003; B.D. vs. ACP Secretariat, Cour d'appel, 27 de fevereiro de 2007.

${ }^{67}$ FRANÇA. UNESCO vs. Boulois, Tribunal de grande instance de Paris, 20 de outubro de 1997. Ver também Banque africaine de développement vs. M.A.Degboe, 25 de janeiro de 2005, Cour de cassation (Chambre sociale).

68 REINISCH, August. International organizations before national courts. Cambridge: Cambridge University Press, 2000.
} 
Pereira Ormond vs. ONU/PNUD, ${ }^{69}$ com posterior repercussão geral reconhecida, em 2017. ${ }^{70}$ De acordo com o entendimento do STF, não importa a natureza do ato realizado pela organização internacional nem a prévia existência de mecanismos internos de solução de controvérsias, mas a averiguação da existência de tratados celebrados pelo Brasil que prevejam a imunidade jurisdicional da organização. Caso o tratado em questão não estabeleça exceção à imunidade, o STF tem entendido que eventual inobservância da imunidade poderia incorrer o Brasil no descumprimento de obrigação internacional previamente pactuada com a organização. Trata-se de aplicação absoluta da imunidade jurisdicional das organizações internacionais. Desde esse julgado, a jurisprudência do Tribunal Superior do Trabalho (TST) também tem reconhecido a imunidade jurisdicional de organizações internacionais de maneira absoluta em matéria trabalhista. Importante destacar, no entanto, que, em relação aos Estados, o STF tem seguido entendimento distinto, que relativiza a imunidade jurisdicional para atos de gestão - embora permaneça absoluta em sede de execução. ${ }^{71}$

Do ponto de vista do ordenamento jurídico interno e da jurisprudência do STF, é possível questionar a prevalência de tratados constitutivos de organizações internacionais e de acordos de sede sobre direitos fundamentais e sobre tratados de direitos humanos. Acordos de sede e tratados constitutivos têm legalidade ordinária, enquanto tratados de direitos humanos, segundo a atual

\footnotetext{
69 BRASIL. Supremo Tribunal Federal (Tribunal Pleno). Recurso Extraordinário. RE $n^{\circ} 578.543 / M T$. Direito internacional público. Direito constitucional. Imunidade de jurisdição. [...]. Relator: Min. Teori Zavascki, 15 de maio de 2013. Disponível em: https://redir.stf. jus.br/paginadorpub/paginador.jsp?docTP $=\mathrm{AC} \& \operatorname{doc} \mathrm{ID}=630068$ Acesso em: 20 jul. 2021; BRASIL. Supremo Tribunal Federal (Tribunal Pleno). Recurso Extraordinário. RE $n^{0}$ 597.368/MT. Direito internacional público. Direito constitucional. Imunidade de jurisdição. [...]. Relatora: Min. Ellen Gracie, 15 de maio de 2013. Disponível em: https://redir.stf.jus.br/paginadorpub/paginador. jsp?docTP=AC\&docID=630069Acesso em: 20 jul. 2021.

${ }^{70}$ BRASIL. Supremo Tribunal Federal (Tribunal Pleno). Recurso Extraordinário. RE $n^{\circ}$ 1034840/DF. Recurso Extraordinário. Organismo internacional. Organização das Nações Unidas ONU [...]. Relator: Min. Luiz Fux, 1 de junho de 2017. Disponível em: https:// stf.jusbrasil.com.br/jurisprudencia/861473641/repercussao-geralno-recurso-extraordinario-rg-re-1034840-df-distrito-federal Acesso em: 20 jul. 2021.

${ }^{71}$ BRASIL. Supremo Tribunal Federal (Tribunal Pleno). Apelação Cível. ACi $n^{\circ}$ 9696-3/SP. Estado estrangeiro. Imunidade judiciária. Causa trabalhista. [...]. Relator: Min. Sydney Sanches, 31 de maio de 1989. Disponível em: https://stf.jusbrasil.com.br/jurisprudencia/905776/apelacao-civel-aci-9696-sp Acesso em: 20 jul. 2021.
}

jurisprudência do STF (RE n. ${ }^{\circ} 349.703$ e n. ${ }^{\circ}$ 466.343), têm caráter normativo supralegal - sem descartar a hipótese do nível constitucional, quando observado o artigo $5^{\circ}$, parágrafo $3^{\circ}$, da Constituição Federal. É questionável, portanto, a compatibilidade entre o posicionamento do STF em relação à imunidade jurisdicional das organizações internacionais e ao status hierárquico dos tratados de direitos humanos no ordenamento jurídico interno. A jurisprudência atual busca preservar a obrigação internacional do Estado brasileiro em garantir a imunidade das organizações internacionais. Todavia, esse entendimento conduz à inobservância de outras obrigações internacionais também assumidas pelo Estado, que se originam de tratados de direitos humanos que contam com status hierárquico superior no direito interno ao das fontes que preveem a imunidade jurisdicional daquelas organizações.

Os casos citados na presente seção demonstram o constante conflito entre a imunidade jurisdicional das organizações internacionais e o direito de acesso à justiça. Ainda que haja tendência em certos tribunais regionais e nacionais em condicionar essa imunidade à existência de mecanismos internos de solução de controvérsias, a prática atual está longe de ser consistente — como bem apontou o Comitê Jurídico Interamericano da OEA. O Brasil é exemplo claro de como a imunidade jurisdicional desses sujeitos de direito ainda pode ser aplicada de maneira absoluta, em que pese os desdobramentos jurisprudenciais na Corte Europeia de Direitos Humanos e em diversos outros tribunais domésticos. Essa interpretação absoluta impede que organizações internacionais sejam responsabilizadas por atos ilícitos, constituindo-se em um dos óbices para o desenvolvimento da responsabilidade internacional desses sujeitos.

\subsection{Entre a relativização da imunidade jurisdicional e o desenvolvimento de mecanismos internos de solução de controvérsias}

Como reconhecido pela OEA, não há condições sólidas para a elaboração de instrumentos vinculantes sobre imunidades jurisdicionais das organizações internacionais, em que pese o trabalho já empreendido pela CDI. Isso implica constatar que, dificilmente, haverá mudanças no arcabouço normativo existente que rege as imunidades das organizações internacionais. Esse 
contexto revela significativa lacuna no sistema internacional que impede a responsabilização das organizações internacionais.

Diante da rigidez do arcabouço normativo atual, deve-se buscar melhorar a aplicação das regras já existentes, sob a perspectiva de que as imunidades não operam de maneira isolada no Direito Internacional Público, uma vez que derivam das mesmas fontes de direito que as demais normas internacionais. ${ }^{72}$ Tampouco devem as imunidades servir de pretexto para a violação de direitos humanos.

A superação dessa lacuna, na seara da responsabilidade internacional, depende, em primeiro lugar, das próprias organizações internacionais. De acordo com os tratados constitutivos, os instrumentos multilaterais e os acordos de sede existentes, cabe às organizações internacionais decidir sobre a renúncia de suas imunidades, caso a caso. A prática atual demonstra, no entanto, que essas organizações têm preferido fazer uso de suas imunidades mesmo quando as circunstâncias as tornam difíceis de justificar, como no caso do surto de cólera no Haiti, analisado no capítulo anterior. Além disso, a ausência de mecanismos internos de solução de controvérsias efetivos impede que o direito de acesso à justiça seja assegurado.

Diante da relutância de renunciar às imunidades jurisdicionais e de desenvolver mecanismos internos de solução de controvérsias, a relativização das imunidades por certos tribunais regionais e domésticos parece servir como alternativa viável para a responsabilização das organizações internacionais. Uma resposta pragmática por parte das organizações internacionais às crescentes tentativas de relativizar sua imunidade jurisdicional seria instituir mecanismos internos de solução de controvérsias e, por conseguinte, suprir lacunas no sistema jurídico internacional que têm impedido o desenvolvimento da prática de responsabilização desses sujeitos. Enquanto as organizações internacionais não forem capazes de preencher essas lacunas, é provável que outros atores do sistema internacional cumpram esse papel, subsidiariamente.

\footnotetext{
72 ORAKHELASHVILI, Alexander. Responsibility and immunities: similarities and differences between international organizations and states. International Organizations Law Review, n. 11, 2014. p. 162.
}

\section{Consideraações finais}

A emergência e a multiplicação das organizações internacionais, bem como a expansão de seus mandatos, contribuíram para institucionalizar a diplomacia multilateral, criar novos canais de diálogos e submeter os Estados à primazia do Direito. Cabe agora buscar o aperfeiçoamento do ordenamento jurídico internacional, o que requererá submeter também as organizações internacionais à primazia do Direito Internacional Público, como corolário do reconhecimento de sua personalidade jurídica.

Anteriormente, questionava-se se as organizações internacionais poderiam cometer atos ilícitos. Atualmente, não mais se questiona essa possibilidade. Conquanto esteja claro que as organizações internacionais podem violar obrigações internacionais, a prática demonstra que esses sujeitos têm sido raramente responsabilizados por atos internacionalmente ilícitos. Há autores que diagnosticam o problema como resultado de lacuna normativa no Direito Internacional Público e buscam, como alternativa pragmática, enfatizar a responsabilidade dos Estados Membros. O presente artigo adota conclusão distinta: os Artigos sobre Responsabilidade das Organizações Internacionais da Comissão de Direito Internacional oferecem base normativa suficiente para a responsabilização das organizações internacionais. Se a prática de responsabilização tem sido limitada, o problema não decorre da falta de regras, mas de óbices de natureza institucional.

Diferentemente dos Artigos sobre Responsabilidade dos Estados, vistos como codificação do direito internacional consuetudinário, os Artigos sobre Responsabilidade das Organizações Internacionais devem ser encarados como desenvolvimento progressivo do direito internacional. A prática internacional limitada tem impedido a adoção formal dos artigos da CDI pelos Membros das Nações Unidas, bem como a emergência de normas costumeiras sobre atribuição de responsabilidade às organizações internacionais.

Uma conclusão precipitada seria destacar a importância de convocação de conferência internacional para a adoção dos Artigos sobre Responsabilidade das Organizações Internacionais. Essa medida asseguraria a esses artigos um lugar formal no rol de fontes do Direito Internacional Público, na forma de tratado. Todavia, a mera existência formal de tal instrumento não seria 
garantia de sua aplicação na prática internacional. Por isso, opta-se por privilegiar a identificação dos óbices jurídico-institucionais que vêm impedindo a responsabilização das organizações internacionais.

O principal óbice ao desenvolvimento consistente de prática de responsabilização das organizações internacionais tem sido a ausência de mecanismos de controle de legalidade internos e externos, o que tem impedido a efetivação das regras de responsabilidade internacional no âmbito do direito internacional. Além disso, outro importante óbice - embora não se possa colocá-lo no mesmo nível de importância do anterior — tem sido a aplicação da imunidade jurisdicional absoluta das organizações internacionais, em que pese a ausência de meios alternativos de solução de controvérsias. A superação desses óbices pode ser alcançada de distintas maneiras.

Medida essencial para tornar as organizações internacionais mais responsáveis é o estabelecimento de mecanismos permanentes de controle interno. Conforme analisado no capítulo terceiro, é possível verificar alguma variedade de mecanismos de controle interno, em geral de baixa densidade institucional. Com poucas exceções, a prática internacional demonstra que essas medidas têm sido insuficientes, sobretudo na agenda de paz e segurança internacional, em que se notam com maior frequência violações de direitos humanos no âmbito de missões de paz e da administração internacional de territórios.

Eventual criação de mecanismos internos de controle deve observar certas medidas essenciais para garantir sua efetividade. Em primeiro lugar, esses mecanismos devem ter natureza permanente e responder diretamente ao órgão máximo de governo da organização internacional, não a órgãos subsidiários. Em segundo, cabe assegurar a publicidade das recomendações desses mecanismos, com prazos para seu cumprimento. Em terceiro, o modelo de justiça local deve ser sempre privilegiado, para garantir o acesso das vítimas a esses mecanismos de controle. Por fim, deve-se garantir que o devido processo, incluindo o princípio do contraditório e da ampla defesa, sejam adotados por esses mecanismos à luz dos padrões e tratados internacionais de direitos humanos.

Além da criação de mecanismos de controle interno, é importante expandir o locus standi in judicio das organizações internacionais, com vistas a assegurar, igual- mente, o controle externo. Em particular, possibilitar o acesso desses sujeitos perante a Corte Internacional de Justiça pode contribuir para torná-los mais responsáveis. Essa medida poderia implicar, no entanto, emendas ao Estatuto da CIJ (artigos 34 e 35) e da Carta das Nações Unidas (artigo 93, parágrafo $2^{\circ}$ ) — o que requereria consenso dos Estados Membros.

Outra grande categoria de desafios para a emergência da prática de responsabilização das organizações internacionais refere-se às imunidades. $\mathrm{O}$ atual sistema normativo que regulamenta as imunidades desses sujeitos sofreu poucas alterações substantivas desde as décadas de 1920 e 1930. É improvável que essas regras sofram alterações ou atualizações tão cedo, considerando os trabalhos e as conclusões da CDI e do Comitê Jurídico Interamericano. Tampouco se pode esperar que seja elaborado instrumento internacional geral sobre o tratamento das imunidades das organizações internacionais. Deve-se, portanto, buscar melhorar a implementação das regras já existentes.

Medida essencial para melhorar a implementação dessas regras é o exercício pelas organizações internacionais de seu poder-dever de renunciar às imunidades em casos de atos não oficiais ou de patente denegação do direito de acesso à justiça. Nesse contexto, seria importante que o secretário-geral de cada organização relatasse periodicamente aos Estados Membros sobre a implementação de seu poder-dever de renúncia. Relatórios dessa natureza permitiriam avaliação informada sobre a quantidade de casos em que as organizações internacionais têm cumprido com essa obrigação, bem como as circunstâncias em que as renúncias têm ocorrido. Essas informações poderiam revelar como tem ocorrido o desenvolvimento da prática internacional a esse respeito.

Cabe destacar que não é a reforma das normas sobre imunidades das organizações internacionais que tornará esses sujeitos mais responsáveis. O cerne do problema está, na realidade, na ausência de mecanismos internos de solução de controvérsias aos quais as vítimas possam recorrer diante de violações de seus direitos. Essa situação pode agravar-se sobremaneira diante de violação de normas de direito internacional geral e de jus cogens.

A Corte Europeia de Direitos Humanos ofereceu uma maneira de superar esse problema, conquanto de maneira paliativa. Em Waite e Kennedy vs. Alemanha, a imunidade jurisdicional das organizações internacionais 
foi condicionada à disponibilidade de garantias judiciais adequadas e efetivas, alternativas às das jurisdições nacionais. Alguns tribunais domésticos passaram a exigir, igualmente, mecanismos de proteção dos direitos fundamentais dentro das organizações internacionais, condicionando as imunidades à sua existência e efetividade. Contudo, não se trata de tendência claramente majoritária. As contribuições jurisprudenciais de tribunais domésticos demonstram que não há consistência na relativização da imunidade jurisdicional das organizações internacionais. O Brasil é exemplo da aplicação absoluta dessas imunidades.

A ausência de mecanismos de controle tem motivado tribunais regionais e domésticos a realizarem o controle de legalidade de atos das organizações internacionais. Esse controle tem sido feito de maneira incidental, na análise de dispositivos regionais ou nacionais que conferem eficácia a atos das organizações internacionais. De maneira similar, a ausência de mecanismos internos de solução de controvérsias também tem levado esses atores a relativizarem a imunidade jurisdicional das organizações internacionais. O papel crescente dos tribunais nacionais e regionais não deixa de ser salutar; no entanto, pode levar a problemas de inconsistências jurisprudenciais e até mesmo a situações de arbitrariedade na limitação das imunidades.

A limitada prática internacional revela a existência, atualmente, de situação de impunidade das organizações internacionais e de denegação sistemática do direito de acesso à justiça. Esse contexto tem servido de justificativa para correntes acadêmicas que buscam enfatizar a responsabilidade dos Estados Membros (shared responsibility), para viabilizar reparações às vítimas de atos internacionalmente ilícitos cometidos por organizações internacionais. É, portanto, do interesse dos próprios Estados Membros fortalecer a personalidade jurídica das organizações internacionais e torná-las mais responsáveis, para que estas possam responder independentemente por seus atos perante mecanismos permanentes de controle interno e tribunais internacionais. Os principais beneficiários dessas reformas serão, em última instância, os indivíduos, que passarão a contar com instituições mais sólidas e com recursos disponíveis e efetivos para exercer o direito de acesso à justiça.

\section{Referências}

ALEMANHA. Hetzel v. EUROCONTROL, Federal Constitutional Court, Second Chamber, 10 de novembro de 1981.

ALEMANHA. Higher Administrative Court of North Rhine-Westphalia, Fourth Chamber, Case No. 4 A 2948/11 (Anonymous v. Federal German Government), judgment, 18 de setembro de 2014.

BARROS, Ana Sofia; RYNGAERT, Cedric; WOUTERS, Jan (eds.) International organizations and member state responsibility: critical perspectives. Leiden: Brill Nijhoff, 2017.

BÉLGICA. Lutchmaya vs. ACP Secretariat. Cour d'appel, Bruxelas, 4 de março de 2003; B.D. vs. ACP Secretariat, Cour d'appel, 27 de fevereiro de 2007.

BÉLGICA. Western European Union v Siedler, Appeal judgment, Case No S 040129 F, ILDC 1625 (BE 2009), 21 de dezembro de 2009, Court of Cassation.

BLOKKER, Niels. International organizations: the untouchables? In: BLOKKER, Niels. Immunity of International Organizations. Leiden: Brill Nijhoff, 2015.

BLOKKER, Niels. Member state responsibility for wrongdoings of international organizations. In: BARROS, Ana Sofia; RYNGAERT, Cedric; WOUTERS, Jan (eds.) International organizations and member state responsibility: critical perspectives. Leiden: Brill Nijhoff, 2017.

BONAFE, Beatrice I. Italian courts and the immunity of international organizations. In: BLOKKER, Niels. Immunity of International Organizations. Leiden: Brill Nijhoff, 2015.

BRASIL. Supremo Tribunal Federal (Tribunal Pleno). Apelação Cível. ACi $n^{0}$ 9696-3/SP. Estado estrangeiro. Imunidade judiciária. Causa trabalhista. [...]. Relator: Min. Sydney Sanches, 31 de maio de 1989. Disponível em: https://stf.jusbrasil.com.br/jurisprudencia/905776/apelacao-civel-aci-9696-sp Acesso em: 20 jul. 2021.

BRASIL. Supremo Tribunal Federal (Tribunal Pleno). Recurso Extraordinário. RE $n^{0}$ 1034840/DF. Recurso Extraordinário. Organismo internacional. Organização das Nações Unidas ONU [...]. Relator: Min. Luiz Fux, 1 de junho de 2017. Disponível em: https:/ / stf.jusbrasil. com.br/jurisprudencia/861473641/repercussao-geral- 
no-recurso-extraordinario-rg-re-1034840-df-distritofederal Acesso em: 20 jul. 2021.

BRASIL. Supremo Tribunal Federal (Tribunal Pleno). Recurso Extraordinário. RE $n^{\circ} 578.543 / M T$. Direito internacional público. Direito constitucional. Imunidade de jurisdição. [...]. Relator: Min. Teori Zavascki, 15 de maio de 2013. Disponível em: https://redir.stf.jus.br/paginadorpub/paginador.jsp?docTP $=$ AC\&docID $=630068$ Acesso em: 20 jul. 2021.

BRASIL. Supremo Tribunal Federal (Tribunal Pleno). Recurso Extraordinário. RE $n^{0}$ 597.368/MT. Direito internacional público. Direito constitucional. Imunidade de jurisdição. [...]. Relatora: Min. Ellen Gracie, 15 de maio de 2013. Disponível em: https:// redir.stf.jus.br/paginadorpub/paginador. jsp?docTP=AC\&docID=630069Acesso em: 20 jul. 2021.

BROWLIE, Ian. Principles of public international law. New York: Oxford University Press, 2008.

BÚRCA, Gráinne de. The European Court of Justice and the international legal order after Kadi. Harvard International Law Journal, v. 51, 2010.

CANÇADO TRINDADE, Antonio Augusto (org.). Repertório da prática brasileira do direito internacional público (período 1961-1981). Brasília: FUNAG, 2012.

CANÇADO TRINDADE, Antonio Augusto. Direito das organizações internacionais. Belo Horizonte: Del Rey, 2014.

CANÇADO TRINDADE, Antonio Augusto. O esgotamento dos recursos internos e a evolução da noção de "vítima" no direito internacional. Revista de Informação Legislativa, v. 23, n. 89, 1986.

CORTE EUROPEIA DE DIREITOS HUMANOS (Grand Chamber). Al-Jedda v. United Kingdom, application No. 27021/08, judgment, 7 de julho de 2011.

CORTE EUROPEIA DE DIREITOS HUMANOS. Beer and Regan vs. Alemanha, Application no. 28934/95. Judgment, 18 de fevereiro de 1999.

CORTE EUROPEIA DE DIREITOS HUMANOS. Behrami and Behrami v. France and Saramati v. France, Germany and Norway. Decisão de 2 de maio de 2007.

CORTE EUROPEIA DE DIREITOS HUMANOS. Case of Beric and others v. Bosnia and Herzegovina, application Nos. 36357/04, 36360/04, 38346/04, 41705/04,
45190/04，45578/04，45579/04，45580/04，91/05, $97 / 05,100 / 05,101 / 05,1121 / 05,1123 / 05,1125 / 05$, $1129 / 05,1132 / 05,1169 / 05,1172 / 05,1175 / 05$, $1177 / 05,1180 / 05,1185 / 05,20793,05$ e $25496 / 05$, decision (admissibility), 16 October 2007.

CORTE EUROPEIA DE DIREITOS HUMANOS. Case of Bosphorus Hava Yollari Turizm Vê Ticaret Anonim Sirketi v. Ireland. In Reports of Judgments and Decisions 2005, VI. Julgamento de 30 de junho de 2005.

CORTE EUROPEIA DE DIREITOS HUMANOS. Stichting Mothers of Srebrenica v. Paises Baixos. Application No. 65542/12, 11 de junho de 2013.

CORTE EUROPEIA DE DIREITOS HUMANOS. Waite and Kennedy vs. Alemanba. Application no. 26083/94. Judgment, 18 February 1999.

CORTE INTERAMERICANA DE DIREITOS HUMANOS. Caso Goiburú e outros v. Paraguai. Mérito, reparações e custas (Série C No. 153). Julgamento de 22 de setembro de 2006.

CORTE INTERNACIONAL DE JUSTIÇA. Application of Article VI, Section 22, of the Convention on the Privileges and Immunities of the United Nations, Advisory Opinion. I.C.J. Reports, 1989.

CORTE INTERNACIONAL DE JUSTIÇA. Certain expenses of the United Nations, Advisory Opinion. I.C.J. Reports, 1962.

CORTE INTERNACIONAL DE JUSTIÇA. Differences relating to immunity from legal process of a Special Rapporteur of the Commission on Human Rights, Advisory Opinion. I.C.J. Reports, 1999.

CORTE INTERNACIONAL DE JUSTIÇA. Effect of awards of compensation made by the United $\mathrm{Na}$ tions Administrative Tribunal, Advisory Opinion. I.C.J. Reports, 1954.

CORTE INTERNACIONAL DE JUSTIÇA. Interpretation of the Agreement of 25 March 1951 between the WHO and Egypt, Advisory Opinion. I.C.J. Reports, 1980.

CORTE INTERNACIONAL DE JUSTIÇA. Judgments of the Administrative Tribunal of the ILO upon complaints made against the UNESCO, Advisory Opinion of October 23 ${ }^{\text {rd }}$. I.C.J. Report, 1956. 
CORTE INTERNACIONAL DE JUSTIÇA. Jurisdictional immunities of the State (Germany v. Italy: Greece intervening), Judgment. ICJ Reports, 2012.

CORTE INTERNACIONAL DE JUSTIÇA. Legal consequences for States of the continued presence of South Africa in Namibia (South West Africa) notwithstanding Security Council Resolution 276 (1970). I.C.J. Reports, 1971.

CORTE INTERNACIONAL DE JUSTIÇA. Legality of the Use by a State of Nuclear Weapons in Armed Conflict. Advisory Opinion. I.C.J. Reports, 1996.

CORTE INTERNACIONAL DE JUSTIÇA. Questions of interpretation and application of the 1971 Montreal Convention arising from the Aerial Incident at Lockerbie (Libyan Arab Jamahiriya v. United Kingdom). I.C.J. Reports, 1992.

CORTE INTERNACIONAL DE JUSTIÇA. Reparations for injuries suffered in the service of the United Nations, Advisory Opinion. I.C.J. Reports, 1949.

CORTE PERMANENTE DE JUSTIÇA INTERNACIONAL. Competence of the International Labour Organization to Regulate, Incidentally, the Personal Work of the Employer. Publications of the Permanent Court of International Justice, n. 13, 23 de julho de 1926.

CORTE PERMANENTE DE JUSTIÇA INTERNACIONAL. Interpretation of the Greco-Turkish Agreement of December 1st, 1926. Publications of the Permanent Court of International Justice, n. 16, 28 de agosto de 1928.

CORTE PERMANENTE DE JUSTIÇA INTERNACIONAL. The case of the S.S. "Lotus". Publications of the Permanent Court of International Justice, n. 10, 7 de setembro de 1927.

COUVREUR, Philippe. Developpements recents concernant l'acces des organizations intergouvernementales a la procedure contentieuse devant la Cour internationale de justice. In:YAKPO, Emile K.; BOUMEDRA, Tahar (eds.). Liber Amicorum Judge Mohammed Bedjaoui. Haia: Nijhoff, 1999.

CRAVIOTO, Alejandro et al. Independent panel of experts on the cholera outbreak in Haiti. 2011. Disponível em: http://www.un.org/News/dh/infocus/haiti/UN-cholera-report-final.pdf Acesso em: 2 dez. 2018.

CRAWFORD, James. The ILC's articles on responsibility of states for internationally wrongful acts: a retro- spect. The American Journal of International Law, v. 96, n. 4, p. 874-890, out. 2002.

D'ASPREMONT, Jean. Bindingness. In: D'ASPREMONT, Jean; SINGH, S. (eds.). Fundamental concepts for international law: the construction of a discipline. USA: Elgar, 2016.

D'ASPREMONT, Jean. Wording in international law. Leiden Journal of International Law, n. 25, 2012.

DUPUY, Pierre-Marie. Le fait générateur de la responsabilité internationale des États. Recueil des Cours de l'Académie de Droit International, v. 188, n. 5, 1984.

ESTADOS UNIDOS DA AMÉRICA. Urban vs. United Nations, D.C. Court of Appeals, 1985.

FASSBENDER, Bardo. Targeted Sanctions and Due Process: the responsibility of the UN Security Council to ensure that fair and clear procedures are made available to individuals and entities targeted with sanctions under Chapter VII of the UN Chapter. Berlim: Humboldt University Berlin, 2006.

FERSTMAN, Carla. International organizations and the fight for accountability. Oxford: Oxford University Press, 2017.

FRANÇA. UNESCO vs. Boulois, Tribunal de grande instance de Paris, 20 de outubro de 1997. Ver também Banque africaine de développement vs. M.A.Degboe, 25 de janeiro de 2005, Cour de cassation (Chambre sociale).

FREEDMAN, Rosa. UN Immunity or impunity? a human rights based challenge. European Journal of International Law, v. 25, n.1, 2014.

FRIEDMANN, Wolfgang. Mudança da estrutura do direito internacional. Rio de Janeiro: Freitas Bastos, 1971.

GALINDO, George Rodrigo Bandeira. "The Second Road": the International Law Commission and the emergence of the distinction between primary and secondary rules in the law of state responsibility. No prelo.

GALINDO, George Rodrigo Bandeira. Tratados internacionais de direitos humanos e constituição brasileira. Belo Horizonte: Del Rey, 2002.

GATTINI, Andrea. Breach of international obligations. In: NOLLKAEMPER, André; PLAKOKEFALOS, Ilias. Principles of shared responsibility in international law: an appraisal of the sate of the art. Cambridge: Cambridge University Press, 2014. 
HAMMARSKJOLD, Ake. Les immunités des personnes investies de fonctions internationales. Recueil des cours, v. 56, 1936.

HART, Herbert L. O conceito de direito. Lisboa: Calouste Gulbenkian, 1996.

HERZ, Steven; PERRAULT, Anne. Bringing human claims to the world bank inspection panel. Center for International Environmental Law, 2009. Disponível em: https://ael.eui.eu/wp-content/uploads/ sites/28/2017/04/Fiti-Sinclair-07-Herz-Perrault.pdf Acesso em: 2 dez. 2018.

INTERNATIONAL CRIMINAL TRIBUNAL FOR THE FORMER YUGOSLAVIA. Cf. caso Prosecutor $v$. Dragan Nikolic (No. IT-94-2-PT).

ITÁLIA. Corte Suprema Italiana. FAO v. Calagrossi, 18 de maio de 1992, No. 5942.

ITÁLIA. Corte Suprema Italiana. FAO v. INPDAI, 18 de outubro de 1982.

KENNEDY, David. The move to institutions. Cardozo Law Review, n. 8, 1987.

KLABBERS, Jan. The life and times of the law of international organizations. In: KLABBERS, Jan (org.). International organizations. Trowbridge: Ashgate Dartmouth, 2005.

KLABBERS, Jan. The transformation of international organizations law. European Journal of International Law, v. 26, n. 1, 2015.

KLEIN, P. The attribution of acts to international organizations. In: CRAWFORD, J; PELLET, A.; OLLESON, S. (eds.). The law of international responsibility. Oxford: Oxford University Press, 2010.

KUHN, Thomas. A estrutura das revoluções científicas. São Paulo: Perspectiva, 2006.

KUIJPER, P. J.; PAASIVIRTA, E. EU international responsibility and its attribution: from the inside looking out. In: EVANS, M.; KOUTRAKOS, P. (eds.). The international responsibility of the European Union. Oxford: Hart Publishing, 2013.

LAMMERS, Johan G. Immunity of international organizations: the work of the International Law Commission. In: BLOKKER, Niels. Immunity of international organizations. Leiden: Brill Nijhoff, 2015.
LAUTERPACHT, Hersch. The grotian tradition in international law. British Yearbook of International Law, v. 23, n. 1, 1946.

MOLL, Leandro de Oliveira. Imunidades internacionais: tribunais nacionais ante a realidade das organizações internacionais. Brasília: FUNAG, 2010.

NOLLKAEMPER, André; PLAKOKEFALOS, Ilias. Principles of shared responsibility in international law: an appraisal of the state of the art. Cambridge: Cambridge University Press, 2014.

OLIVEIRA, Carina Costa de. Comentário à Opinião Consultiva n. 21 do Tribunal Internacional para o Direito do Mar: responsabilidade do Estado de Bandeira pela pesca ilícita, não declarada ou não regulamentada. Revista de Direito Internacional, v. 12, 2015.

OLLESON, Simon. Internationally wrongful acts in the domestic courts: the contribution of domestic courts to the development of customary international law relating to the engagement of international responsibility. Leiden Journal of International Law, v. 26, n. 3, 2013.

ORAKHELASHVILI, Alexander. Responsibility and immunities: similarities and differences between international organizations and states. International Organizations Law Review, n. 11, 2014.

ORAKHELASHVILI, Alexander. The acts of the security council: meaning and standards of review. Max Planck Yearbook of United Nations Law, v. 11, 2007.

ORGANIZAÇÃO MUNDIAL DO COMÉRCIO. Relatório do painel no caso EC - Protection of Trademarks and Geographical Indications for Agricultural Products and Foodstuf$f s$ - Complaint by the United States. WT/DS174/R, adotado em 20 de abril de 2005.

PAASIVIRTA, E. Responsibility of a member state of an international organization: where will it end? comments on Article 60 of the ILC Draft on the Responsibility of International Organizations. International Organizations Law Review, v. 7, n. 49, p. 49-61, 2010.

PAÍSES BAIXOS. Court of Appeal of The Hague. Mustafic-Mujic v. State of the Netherlands, case No. 200.020.173/01, judgment, 5 de julho de 2011; Nuhanovic v. State of the Netherlands, case No. 200.020.174/01, judgment, 5 de julho de 2011.

PAÍSES BAIXOS. District Court of The Hague. Mustafic-Mujic v. State of the Netherlands, case No. 265618/HA ZA 06-1672, judgment, 10 de setembro de 2008. 
PAÍSES BAIXOS. District Court of The Hague. Stitching Mothers of Srebrenica and Others v. State of the Netherlands, case No. C/09/295247/HA ZA 07-2973, judgment, 16 de julho de 2014.

PAÍSES BAIXOS. Supreme Court of the Netherlands (First Chamber). State of the Netherlands v. MustaficMujic, case No. 12/03329, judgment, 6 de setembro de 2013; State of the Netherlands v. Nuhanovic, case No. 12/03324, judgment, 6 de setembro de 2013.

PAÍSES BAIXOS. Supreme Court of the Netherlands. Mother of Srevrenica et al v. State of The Netherlands and the United Nations, case 10/04437, judgment, 13 de abril de 2012.

PALCHETTI, Paolo. The law of responsibility of international organizations: general rules, special regimes or alternative mechanisms of accountability? Anuário Brasileiro de Direito Internacional, v. 2, p. 72-88, 2015.

QUOC DINH, Nguyen; PELLET, Alain; DAILLIER, Patrick. Direito Internacional Público. Lisboa: Fundação Calouste Gulbenkian, 1999.

REINISCH, A. Aid or assistance and direction and control between state and international organizations in the commission of internationally wrongful acts. International Organizations Law Review, v. 7, n. 63, p. 63-77, 2010.

REINISCH, August. International organizations before national courts. Cambridge: Cambridge University Press, 2000.

REINISCH, August. To what extent can and should national courts fill the accountability gap? In: BLOKKER, Niels. Immunity of International Organizations. Leiden: Brill Nijhoff, 2015.

REINISCH, August; WEBER, Ulf Andreas. In the shadow of Waite and Kennedy: the jurisdictional immunity of international organizations, the individual's right of access to the courts and administrative tribunals as alternative means of dispute settlement. International $\mathrm{Or}$ ganizations Law Review, n. 1, 2004.

REINO UNIDO. Câmara dos Lordes do Reino Unido, sessão 2007-2008, vol. 58, ano 2007. Opinions of the Lords of Appeal for Judgment in the cause Al-Jedda v Secretary of State for Defence. Session 2007-08 [2007] UKHL 58.
REINO UNIDO. Royal Court of Justice (England and Wales High Court, Queen's Bench Division). Kontic and others v. Ministry of Defence, case No. HQ14X02291, judgment, 4 de agosto de 2016.

REINO UNIDO. Royal Courts of Justice. Serdar Mohammed and Others v. Ministry of Defence.

SCELLE, Georges. Règles générales du droit de la paix. In: COLLECTED Courses of the Hague Academy of International Law. Hague: Hague Academy of International Law, 1933.

SENA, Pasquale de; VITUCCI, Maria Chiara. The European Courts: between dédoublement fonctionnel and balancing of values. European Journal of International Law, v. 20, 2009.

SUREDA, Andrés Rigo. The evolution of the independence of internal judicial and quasi-judicial organs of international organizations: the case of the World Bank. In: ELIAS, Olufemi. The development and effectiveness of international administrative law. Leidn: Martinus Nijhoff, 2012.

TRIBUNAL EUROPEU de Justiça. Opinion of Advocate General Poiares Maduro, de 16 de janeiro de 2008. Casos C-402/05 P e C-415/05 P.

TRIBUNAL INTERNACIONAL PARA O DIREITO DO MAR. Responsibilities and obligations of States with respect to activities in the Area, Advisory Opinion. ITLOS Reports 2011, 1 de fevereiro de 2011.

TRINDADE, Vinícius Fox Drummond Cançado. Controle de legalidade dos atos do Conselho de Segurança das Nações Unidas. Revista da Faculdade de Direito da UFMG, n. 62, 2013.

TRINDADE, Vinícius Fox Drummond Cançado. Governo das Nações Unidas? a administração internacional de territórios. Juca, diplomacia e humanidades, n. 8, 2015. UNIÃO EUROPEIA. Tribunal de Justiça. Acórdão de 3 de setembro de 2008. Caso Yassin Abdullah Kadi, Al Barakkat International Foundation $v$. Conselho da União Européia \& Comissão das Comunidades Europeias, Reino Unido da Grã-Bretanha e da Irlanda do Norte. C 285/2, 8 de novembro de 2008.

VELASCO, Manuel Diez de. Las organizaciones internacionales. Madri: Tecnos, 2008. 
VERDROSS, Alfred. Derecho internacional publico. Madrid: Aguilar, 1976.

WET, Erika de. The chapter VII powers of the United Nations Security Council. Oxford: Hart Publishing, 2004.

YASUAKI, Onuma. International law in and with international politics: the functions of international law in international society. European Journal of International Law, v. 14, n. 1, 2003. 
Para publicar na Revista de Direito Internacional, acesse o endereço eletrônico www.rdi.uniceub.br ou www.brazilianjournal.org.

Observe as normas de publicação, para facilitar e agilizar o trabalho de edição. 